\title{
Exposure of bovine oocytes and embryos to elevated non-esterified fatty acid concentrations: integration of epigenetic and transcriptomic signatures in resultant blastocysts
}

\author{
K. L. J Desmet ${ }^{1 *}$, V. Van Hoeck' ${ }^{1}$ D. Gagné ${ }^{2}$, E. Fournier ${ }^{2}$, A. Thakur ${ }^{3}$, A. M. O'Doherty ${ }^{4}$, C. P. Walsh ${ }^{5}$, M. A. Sirard ${ }^{2}$, \\ P. E. J. Bols ${ }^{1}$ and J. L. M. R. Leroy ${ }^{1}$
}

\begin{abstract}
Background: Metabolic stress associated with negative energy balance in high producing dairy cattle and obesity in women is a risk factor for decreased fertility. Non-esterified fatty acids (NEFA) are involved in this pathogenesis as they jeopardize oocyte and embryo development. Growing evidence indicates that maternal metabolic disorders can disturb epigenetic programming, such as DNA methylation, in the offspring. Oocyte maturation and early embryo development coincide with methylation changes and both are sensitive to adverse environments. Therefore, we investigated whether elevated NEFA concentrations affect establishment and maintenance of DNA methylation in oocytes and embryos, subsequently altering transcriptomic profiles and developmental competence of resultant blastocysts.

Results: Bovine oocytes and embryos were exposed to different NEFA concentrations in separate experiments. In the first experiment, oocytes were matured in vitro for $24 \mathrm{~h}$ in medium containing: 1) physiological ("BASAL") concentrations of oleic (OA), palmitic (PA) and stearic (SA) acid or 2) pathophysiological ("HIGH COMBI") concentrations of OA, PA and SA. In the second experiment, zygotes were cultivated in vitro for 6.5 days under BASAL or HIGH COMBI conditions. Developmental competence was evaluated by assessing cleavage and blastocyst rate. Overall gene expression and DNA methylation of resultant blastocysts were analyzed using microarray. DNA methylation data were re-evaluated by pyrosequencing. HIGH COMBI-exposed oocytes and embryos displayed a lower competence to develop into blastocysts compared to BASAL-exposed counterparts (19.3\% compared to 23. $2 \%$ and $18.2 \%$ compared to $25.3 \%$, respectively) $(P<0.05)$. HIGH COMBI-exposed oocytes and embryos resulted in blastocysts with altered DNA methylation and transcriptomic fingerprints, compared to BASAL-exposed counterparts. Differences in gene expression and methylation were more pronounced after exposure during culture compared to maturation suggesting that zygotes are more susceptible to adverse environments. Main gene networks affected were related to lipid and carbohydrate metabolism, cell death, immune response and metabolic disorders.

(Continued on next page)
\end{abstract}

\footnotetext{
* Correspondence: karolien.desmet@uantwerpen.be

${ }^{1}$ Laboratory of Veterinary Physiology and Biochemistry, Department of

Veterinary Sciences, Faculty of Pharmaceutical, Biomedical and Veterinary

Sciences, University of Antwerp, Wilrijk, Belgium

Full list of author information is available at the end of the article
} 
(Continued from previous page)

Conclusions: Overall, high variation in methylation between blastocysts made it difficult to draw conclusions concerning methylation of individual genes, although a clear overview of affected pathways was obtained. This may offer clues regarding the high rate of embryonic loss and metabolic diseases during later life observed in offspring from mothers displaying lipolytic disorders.

Keywords: Oocyte, Embryo, Fertility, Free fatty acids, Maternal metabolism, DNA methylation, Epigenetics

\section{Background}

Non-esterified fatty acid (NEFA) concentrations are a common feature of an impaired maternal metabolism, typically observed in cows suffering negative energy balance but also in obese and type-II diabetes patients. Earlier research has revealed that the fertility of females suffering from these metabolic disorders is compromised [1]. Awareness grows that NEFAs within the gamete's and/or embryonic microenvironment may play a key role in causing this compromised fertility outcome [2]. Using a bovine model, we and others have previously shown that elevated NEFA concentrations during oocyte maturation and embryo culture are detrimental for embryonic development $[1,3]$. Additionally, elevated NEFA levels in the oocyte's microenvironment can affect gene expression, DNA methylation at imprinted genes and alter the phenotype of resultant blastocysts [4-6]. Lower cell numbers and increased apoptosis were observed in blastocysts after exposure of oocytes to elevated NEFA concentrations. Moreover, these blastocysts displayed reduced pyruvate, glucose and oxygen consumption, increased lactate consumption and altered amino acid metabolism compared to control blastocysts [4]. Notably, oocyte maturation under high NEFA concentrations significantly altered the expression of genes involved in establishing methylation patterns in the matured cumulus oocyte complex, as well as in resultant day 7.5 blastocysts [5, 7]. Cumulus cells from HIGH COMBI-exposed oocytes exhibited down-regulated expression of DNMT3A [7], which is involved in de novo methylation of cytosine residues at CpG sites in oocytes and early preimplantation embryos until embryonic genome activation $[8,9]$. This finding also raises the possibility of altered methylation status due to exposure to adverse maternal metabolic conditions.

Genes regulating DNA methylation, e.g. DNMTs, are crucial for driving appropriate growth and differentiation in the developing embryo, especially during oocyte maturation and early embryo development [9-12]. In the oocyte, an increase in DNA methylation occurs during its growth with the highest level reached at the germinal vesicle stage $[13,14]$. Following fertilization, DNA demethylation takes place in the zygote and continues in the subsequent cleavage stages [15]. Re-establishment of general DNA methylation patterns succeeds embryonic genome activation [16]. At the time of blastocyst formation, DNA remethylation is still an ongoing process that depends on blastocyst's stage, gender and ratio of inner cell mass (ICM) versus trophectoderm (TE) [17]. During post-blastocyst development, cell differentiation occurs with the establishment of cell lineage-specific DNA methylation patterns $[17,18]$. Taken together, it is now generally accepted that oocyte maturation and preimplantation embryo development are sensitive windows for epigenetic reprogramming [19].

Biochemical changes in the oocytes microenvironment, associated with maternal metabolic disturbances [20-22], may result in alterations to the epigenome that, in turn, can compromise fertility or even result in persistent changes during fetal development or become visible after birth [23]. This concept is known as 'Developmental Origins of adult Health and Disease' or DOHAD, first described by Barker et al. [24]. In this context, Ge et al. [25] reported that maternal diabetes mellitus can affect DNA methylation imprinting in murine oocytes. Jungheim et al. [26] showed that mouse embryos, exposed to elevated palmitic acid concentrations, presented an altered embryonic metabolism and development, with lasting adverse effects on growth patterns in offspring suggested to be associated with aberrant epigenetic programming. Assisted reproduction techniques have also been shown to influence epigenetic mechanisms during oocyte maturation and preimplantation embryo culture, leading to, for example, large offspring syndrome in ruminants [27] or a higher risk for metabolic syndrome in children born after in vitro fertilisation $[28,29]$.

We hypothesize that elevated NEFA concentrations during oocyte maturation or embryo culture, the most sensitive windows during which DNA methylation reprogramming occurs, jeopardize embryo developmental competence by impacting the blastocysts transcriptome and DNA methylation signatures. Considering the dynamic properties of DNA methylation at blastocyst stage [17], we propose to focus first on overall affected pathways rather than on gene-specific changes. Therefore, the aim of the present study was to examine the effect of elevated NEFA concentrations during $24 \mathrm{~h}$ of oocyte maturation or during 6.5 days of embryo culture on:

1. transcriptome signatures of resultant day 7.5 blastocysts and, in particular, the expression of genes involved in epigenetic pathways using the bovine EmbryoGENE microarray technique, 
2. whole-genome DNA methylation signatures of resultant day 7.5 blastocysts using the EmbryoGENE DNA

Methylation Array (EDMA, http://embbioinfo.fsaa.ulaval.ca/).

\section{Methods}

\section{Experimental design}

The types and concentrations of free fatty acids used in this study are based on bovine in vivo studies in serum and follicular fluid during a period of negative energy balance [30] and have been reported for in vitro use before by Van Hoeck et al. [4]. Valckx et al. [22] also observed that palmitic (PA, C16:0), stearic (SA, C18:0) and oleic acid (OA, C18:1) are the most abundant NEFAs in human follicular fluid of obese patients.

Two experiments were set up to characterize the developmental capacity and the transcriptomic and epigenomic profile of the resultant day 7.5 blastocysts.

In the first (in vitro maturation or IVM) experiment, the effect of elevated NEFA exposure during oocyte maturation $(24 \mathrm{~h})$ on embryo development, gene expression and DNA methylation profiles was evaluated by exposing oocytes to the following conditions:

1. BASAL: physiological NEFA concentrations $(72 \mu \mathrm{M}$ total NEFA containing $28 \mu \mathrm{M} \mathrm{SA}, 23 \mu \mathrm{M}$ PA, and $21 \mu \mathrm{M} \mathrm{OA})$.

2. HIGH COMBI: a combination of elevated NEFA concentrations equivalent to those measured in the follicular fluid during severe lipolytic conditions (425 $\mu \mathrm{M}$ total NEFA, containing $75 \mu \mathrm{M} \mathrm{SA}, 150 \mu \mathrm{M}$ $\mathrm{PA}$, and $200 \mu \mathrm{M} \mathrm{OA})$.

In the second (in vitro culture or IVC) experiment, the effect of elevated NEFA exposure during embryo culture (6.5 days) on embryo development, gene expression profile and DNA methylation was evaluated by exposing embryos to the following conditions:

1. BASAL: physiological NEFA concentrations $(72 \mu \mathrm{M}$ total NEFA containing $28 \mu \mathrm{M} \mathrm{SA}, 23 \mu \mathrm{M}$ PA, and $21 \mu \mathrm{M} \mathrm{OA})$.

2. HIGH COMBI: a combination of elevated NEFA concentrations equivalent to those measured in serum under high lipolytic conditions (720 $\mu \mathrm{M}$ total NEFA, containing $280 \mu \mathrm{M} \mathrm{SA}, 230 \mu \mathrm{M}$ PA, and $210 \mu \mathrm{M} \mathrm{OA})$.

In order to evaluate the effects of elevated NEFA exposure on embryo development, cleavage rate ( $48 \mathrm{~h}$ p.i.) and blastocyst yield (7.5 days p.i.) were recorded in both experiments. Evaluation of the gene expression profile of blastocysts originating from NEFA-exposed oocytes was previously performed by Van Hoeck et al. [5]. In the IVC experiment, 4 replicates were produced to investigate overall gene expression (using a total of 648 oocytes equally distributed between treatments). Resultant day 7.5 blastocysts were snap frozen for genome-wide analysis of transcription (80 blastocysts, equally collected between treatments in 4 replicates). Blastocysts from NEFA-exposed oocytes (IVM experiment) and embryos (IVC experiment) were produced for genome-wide analysis of DNA methylation profiles. A total of 1039 and 1412 oocytes were used respectively, equally distributed between treatments in 4 replicates. Resultant day 7.5 blastocysts were snap frozen for subsequent DNA methylation analysis (80 blastocysts in each experiments, equally allocated between treatments in 4 replicates). Results obtained from the EDMA analysis were assessed using pyrosequencing of 4 independent replicates of blastocysts in the IVM and IVC experiment (879 and 809 oocytes respectively, equally distributed between treatments). Pools of 10 blastocysts were snap frozen per treatment and per replicate in both experiments.

\section{Preparation of NEFA treatments}

Media containing NEFAs were prepared as previously described by Van Hoeck et al. [4]. SA, PA and OA were dissolved in a stock solution of pure ethanol at different concentrations according to the experiment and treatment. In the IVM experiment, NEFA stocks were prepared at concentrations of 28,23 and $21 \mathrm{mM}$ for the BASAL treatment and 25, 150 and $200 \mathrm{mM}$ for the HIGH COMBI treatment. In the IVC experiment, NEFA stocks were prepared at concentrations of 28,23 and $21 \mathrm{mM}$ for the BASAL treatment and 112, 230 and $210 \mathrm{mM}$ for the HIGH COMBI treatment, respectively. The final medium was supplemented with fatty acid-free $0.75 \%$ bovine serum albumin (BSA) in order to improve NEFA solubility.

\section{In vitro embryo production}

In vitro embryo production procedures were performed as previously described by Van Hoeck et al. [4], using immature oocytes retrieved from bovine ovaries collected from a local abattoir within $2 \mathrm{~h}$ of slaughter. Briefly, grade I cumulus oocyte complexes (COCs) were matured in groups of 50-60 in $500 \mu \mathrm{l}$ serum-free maturation medium containing TCM199 supplemented with fatty acid-free $0.75 \% \mathrm{BSA}, 0.4 \mathrm{mM}$ glutamine, $0.2 \mathrm{mM}$ sodium pyruvate, $0.1 \mathrm{mM}$ cysteamine, $50 \mathrm{mg} / \mathrm{ml}$ gentamycin and murine epidermal growth factor (mEGF, $20 \mathrm{ng} / \mathrm{ml}$ ) for $24 \mathrm{~h}$ in humidified air with $5 \% \mathrm{CO}_{2}$ at $38.5^{\circ} \mathrm{C}$. In the IVM experiment, oocytes were randomly divided in equal groups between treatment-specific maturation media. In the IVC experiment, oocytes were matured in serum-free maturation medium as mentioned above. After IVM, COCs were co-incubated in groups of $100-120$ with spermatozoa at a final concentration of $10^{6} / \mathrm{ml}$ for $22 \mathrm{~h}$ at $38.5^{\circ} \mathrm{C}$ in $500 \mu \mathrm{l}$ fertilization medium (containing $114 \mathrm{mM} \mathrm{NaCl}$, 
$3.1 \mathrm{mM} \mathrm{KCl}, 0.3 \mathrm{mM} \mathrm{Na} 2 \mathrm{HPO}_{4}, 2.1 \mathrm{mM} \mathrm{CaCl} 2-2 \mathrm{H}_{2} \mathrm{O}$, $0.4 \mathrm{mM} \mathrm{MgCl} 2-6 \mathrm{H}_{2} \mathrm{O}, 25 \mathrm{mM}$ bicarbonate, $1 \mathrm{mM}$ pyruvate, $36 \mathrm{mM}$ lactate, $2 \mu \mathrm{L} / \mathrm{ml}$ phenol red, $6 \mathrm{mg} / \mathrm{mL}$ fatty acid-free BSA, $50 \mu \mathrm{g} / \mathrm{mL}$ gentamycin and $0.72 \mathrm{U} / \mathrm{mL}$ heparin) in a humidified $5 \% \mathrm{CO}_{2}$ incubator. Presumptive zygotes were cultured in groups of $25 \pm 4$. During the IVM experiment, the presumptive zygotes were cultured in $50 \mu \mathrm{l}$ droplets of mSOF medium with a mineral oil overlay (modular incubator: $38.5{ }^{\circ} \mathrm{C}, 5 \% \mathrm{CO}_{2}, 5 \% \mathrm{O}_{2}$ and $90 \% \mathrm{~N}_{2}$ ) until the day of analysis. During the IVC experiment, the presumptive zygotes were incubated in a reduced surface 96-well dish containing $75 \mu \mathrm{l}$ medium without mineral oil overlay (modular incubator: $38.5{ }^{\circ} \mathrm{C}$, $5 \% \mathrm{CO}_{2}, 5 \% \mathrm{O}_{2}$ and $90 \% \mathrm{~N}_{2}$ ). The mSOF medium contained $108 \mathrm{mM} \mathrm{NaCl}, 7.2 \mathrm{mM} \mathrm{KCl}, 1.2 \mathrm{mM} \mathrm{KH}_{2} \mathrm{PO}_{4}$, $0.8 \mathrm{mM} \mathrm{MgSO} 4.7 \mathrm{H}_{2} \mathrm{O}, 0.6 \mathrm{mM}$ sodium lactate, $25 \mathrm{mM}$ $\mathrm{NaHCO}_{3}, 0.0266 \mathrm{mM}$ phenol red, $0.73 \mathrm{mM}$ sodium pyruvate, $1.78 \mathrm{mM} \mathrm{CaCl}_{2} .2 \mathrm{H}_{2} \mathrm{O}, 0.34 \mathrm{mM}$ trisodium citrate, $2.755 \mathrm{mM}$ myoinositol, 3\% $v / v$ BME 50x, 1\% $v / v$ MEM $100 \mathrm{x}, 0.4 \mathrm{mM}$ glutamine, $5 \%$ fetal bovine serum and $50 \mu \mathrm{g} / \mathrm{mL}$ gentamycin. For the IVC experiment, NEFAs were added to the mSOF medium at concentrations according to the treatment.

\section{Transcriptomic analysis}

Gene expression analysis using the bovine EmbryoGENE microarray slides was performed as previously described by Cagnone et al. [31]. Total RNA from pools of 10 blastocysts (pools of normal and expanded blastocysts, equally distributed per treatment and per replicate) was extracted and purified using the PicoPure RNA Isolation Kit (ThermoFisher Scientific, Ottawa, Ontario). After DNase treatment (Qiagen, Toronto, Canada), quality and concentration of the extracted RNA were analysed using a bioanalyzer (Agilent, Diegem, Belgium). All extracted samples showed good quality with an RNA integrity number $>7.5$. In total, 42,242 total probes were covered including 21,139 known reference genes, 9,322 probes for novel transcribed regions, 3,677 alternatively spliced exons, 3,353 39-tiling probes, and 3,723 control probes.

\section{Quantification of DNA methylation patterns}

DNA methylation analysis using the bovine EmbryoGENE DNA Methylation Array (EDMA) was performed as previously described by Shojaei et al. [32]. Genomic DNA and total RNA were extracted from pools of 10 blastocysts (pools of normal and expanded blastocysts, equally distributed per treatment and per replicate). The microarray covered a total of 414,566 probes surveying 20,355 genes and 34,379 CpG islands. Data handling was conducted using a built-in pipeline to perform preprocessing (data quality control and normalization) and analysis steps (statistical analysis and data sorting) [32] (http://emb-bioinfo.fsaa.ulaval.ca/).
Targeted DNA methylation analysis using pyrosequencing DNA was isolated from a pool of 10 blastocysts (pools of normal and expanded blastocysts, equally distributed per treatment and per replicate) and bisulfite converted using the EZ methylation direct method (Zymo Research, Freiburg, Germany) following the manufacturer's guidelines. PCR reactions were carried out using the primers summarized in Table 1 . Each PCR reaction contained $16.75 \mu \mathrm{l} \mathrm{H}_{2} \mathrm{O}, 2.5 \mu \mathrm{l} 10 \mathrm{x}$ Buffer, $0.5 \mu \mathrm{l}$ dNTPS $(10 \mathrm{mM})$, $0.5 \mu \mathrm{l}$ forward and reverse primer $(10 \mu \mathrm{M}), 0.25 \mu \mathrm{l}$ Platinum Taq DNA polymerase, $1 \mu \mathrm{lgCl}_{2}(50 \mathrm{mM})$ and $3 \mu \mathrm{l}$ bisulfite DNA template (all products were purchased from Invitrogen Life Technologies). Amplification was as follows: $95{ }^{\circ} \mathrm{C}$ for $5 \mathrm{~min}$, then $40 \mathrm{x} 95^{\circ} \mathrm{C}$ for $30 \mathrm{~s}$, variable annealing temperature (see Table 1 ) for $30 \mathrm{~s}, 72{ }^{\circ} \mathrm{C}$ for $30 \mathrm{~s}$ and finally $72{ }^{\circ} \mathrm{C}$ for $30 \mathrm{~s}$. Pyrosequencing was carried out on a Pyromark Q24 instrument (Qiagen) as described by Rutledge et al. [8]. Selection of the re-evaluated genes was based on involvement in the most important pathways (mentioned in the results) and that were also present in the top 10 list of differentially methylated genes in IPA to validate changes in DNA methylation of physiologically relevant genes.

\section{Statistical analyses}

All statistical analyses of developmental competence data were carried out with SPSS 22 (for Windows, Chicago, IL, USA). Cleavage and blastocyst rates were compared between the treatments (BASAL and HIGH COMBI) using a binary logistic regression model. Replicate (random factor), treatment (fixed factor) and their interaction were taken into account. Differences were considered as being significant at $P<0.05$ and as indicating a trend at $0.05<P<0.1$.

Relative transcript abundance generated through microarray was analysed with FlexArray; statistical data analysis software for gene expression microarrays. Specifically, raw data were corrected by background subtraction, and then normalized within and between each array (Loess and Quantile, respectively). Statistical comparison between treatments was done with the Limma algorithm. A fold change cut-off of 1.5 with $P<0.05$ was set to identify genes whose expression was significantly differentially regulated. Data were analyzed by Ingenuity Pathways Analysis (IPA; Ingenuity Systems, www.ingenuity.com) software, which served to identify pathways that were differentially expressed between treatments.

Bioinformatic analysis of the EDMA results was performed as described by Shojaei et al. [32]. Briefly, the Limma Bioconductor package was used to apply loess intra-array normalization followed by Quantile inter-array scale normalization to draw the intensities. Normalized intensities were then fitted to a linear model and Bayesian statistics of differential expression were obtained. Probes 
Table 1 Primers and annealing temperatures used for pyrosequencing

\begin{tabular}{|c|c|c|c|c|}
\hline & Forward primer & Reverse primer & Sequencing primer & $\begin{array}{l}\text { Annealing } \\
\text { temperature }\end{array}$ \\
\hline COL6A3 & AGGGAAGGTTGTTTAGAGGA & ACCTAAAAATACTAATAACTAATCCATCA & GGTTITATATATAAGTAAAAGAA & $57^{\circ} \mathrm{C}$ \\
\hline APAF1 & TTGGATGTITGTTAGATTGTAGTT & AACTTACCACTACTACCCTCTAC & ATTGGGTITGTGTG & $54^{\circ} \mathrm{C}$ \\
\hline RFC4 & TATITAAAGGAGATTAGTITGGGTGTT & СTCAATTCAATCATAACTCAATCCTATA & ATTGATGTTGAGGTTGAAA & $60^{\circ} \mathrm{C}$ \\
\hline PLSCR3 & TGGTITTGTTGTTTGGTAGTTAAT & CTCATATAACCAAACCCTTAATCTATC & AGTTTITTATTTTAGTAGTTGG & $54{ }^{\circ} \mathrm{C}$ \\
\hline ELOVL1 & GTTTGTAGAGTTGGTGAGTGTA & ATTTACTATCTAACCAAATCACTTCAC & AGTTGGTGAGTGTATG & $59^{\circ} \mathrm{C}$ \\
\hline TBKBP1 & AGAGATGAGAAGGTTAGAGATTAAAGTAT & AACCCTACCACATCTACATCCTCATA & GTITTAAATTAGTTGGGAGATA & $58^{\circ} \mathrm{C}$ \\
\hline ERCC1 & TITTAGTTGGATATATAGATATGGGA & ACTCAACCCCACTCATCT & GGATATATAGATATGGGAAATATT & $52{ }^{\circ} \mathrm{C}$ \\
\hline CELF2 & AGGAGAGAGGTGGTAATAATAAAGTTATA & AACCAAAACCCTTTTCTCCA & GTTGGTGATGAATTTGTAG & $53^{\circ} \mathrm{C}$ \\
\hline ZFAND6 & TGGGGAGGAGTATATGTGTATT & СТTATTCTACСATTACTACTATTСТATCTT & ATATGTGTATTIIIIITTATTATAT & $55^{\circ} \mathrm{C}$ \\
\hline PREX1 & GGTTGGGTATTTATGTTTAGAAATTAAGT & АССТТСТСТАТАATATTТАТTССТСТАСС & ATTAAGTGAGAAGGTATTTG & $56^{\circ} \mathrm{C}$ \\
\hline APPL2 & GTAGGTTITATGGGGAAATTATGTAT & TTCCATACCCTACCTATAAAAAATCTTC & GTIIIIIIIITATTGGGTAGA & $55^{\circ} \mathrm{C}$ \\
\hline GCLC & GTTAAATGGATGAGGGAGTTTAT & ATTTACTTCCACTATACCTAACTIT & TGAATTATAGTITIITITAAAAGTG & $52^{\circ} \mathrm{C}$ \\
\hline
\end{tabular}

that exhibited a $P$-value $<0.05$ and an absolute $\log ^{2}$ fold-change of at least 1.5 were considered differentially methylated regions (DMRs). Probes were categorized based on their genomic locations, CpG islands-related characteristics and the type of repeated elements covered. Enrichment ratios were calculated by comparing the proportion of probes in a given category across the whole array to the same proportion within the DMRs. Data were analyzed by Ingenuity Pathways Analysis (IPA; Ingenuity Systems, www.ingenuity.com) software, which served to identify pathways that were differentially methylated between treatments. For interpretation of individual differentially methylated regions, a Benjamini-Hochberg correction was applied to all $P$-values in order to correct for multiple testing, thus reducing the chance of false positives.

Statistical analyses of the pyrosequencing results were performed using the software package $\mathrm{R}$, version 3.1.2. For each gene, several CpG islands were tested in different replicates, which created dependencies between the observations. To account for the dependence between observations within the same $\mathrm{CpG}$ island and the same replicate a linear mixed model was fitted, where these dependencies were taken into account by including random effect terms into the model. The treatments (BASAL and HIGH COMBI) were entered as fixed effects. The significance of the fixed effect was tested using an F-test with a KenwardRoger correction for the degrees of freedom.

\section{Results}

Experiment 1. Blastocysts originating from NEFA-exposed oocytes: consequences on gene expression and DNA methylation signatures

Part 1A. Developmental competence of blastocysts originating from NEFA-exposed oocytes

Cleavage rates of oocytes matured under HIGH COMBI conditions $(74.1 \%)$ were not significantly different compared to BASAL conditions $(72.3 \%)(P>0.05)$. However, exposing oocytes to HIGH COMBI conditions resulted in a significant reduction of the proportion of oocytes reaching the blastocyst stage at day 7.5 p.i. (19.3\%) compared to BASAL-exposed oocytes $(23.2 \%)(P<0.05)$. There was also a significantly lower capacity of cleaved zygotes to develop to the blastocyst stage in the HIGH COMBI group (26.0\%) compared to the BASAL group (32.1\%) $(P<0.05)$. Data on developmental competence are presented in Table 2 .

Part 1B. Assessment of DNA methylation patterns using EDMA Comparison of the methylome profile between blastocysts originating from HIGH COMBI-exposed and BASALexposed oocytes indicated that 395 loci were differentially methylated $(P<0.05$ and fold change $>1.5)$. More specifically, 240 loci were hypermethylated in the embryos originating from HIGH COMBI-exposed oocytes as compared to embryos originating from BASAL-exposed oocytes; whereas, DNA methylation at 155 loci was significantly lower in the HIGH COMBI group as compared to the BASAL counterparts as shown in Fig. 1.

Enrichment analysis of the data also identified which specific genomic features (genomic localisation and distance to $\mathrm{CpG}$ islands) were present in blastocysts derived from HIGH COMBI-exposed oocytes and this

Table 2 Developmental competence of bovine oocytes exposed to elevated NEFA concentrations during $24 \mathrm{~h}$ of in vitro maturation

\begin{tabular}{lll}
\hline $\mathrm{n}(\%)$ & BASAL & HIGH COMBI \\
\hline Oocytes & 990 & 928 \\
Cleaved & $716(72.3)$ & $688(74.1)$ \\
Blastocysts from oocytes matured & $230(23.2)^{\mathrm{a}}$ & $179(19.3)^{\mathrm{b}}$ \\
Blastocysts from cleaved zygotes & $230(32.1)^{\mathrm{a}}$ & $179(26.0)^{\mathrm{b}}$ \\
\hline
\end{tabular}

Data indicated with different letters (ab) per row are significantly different $(P<0.05)$ 


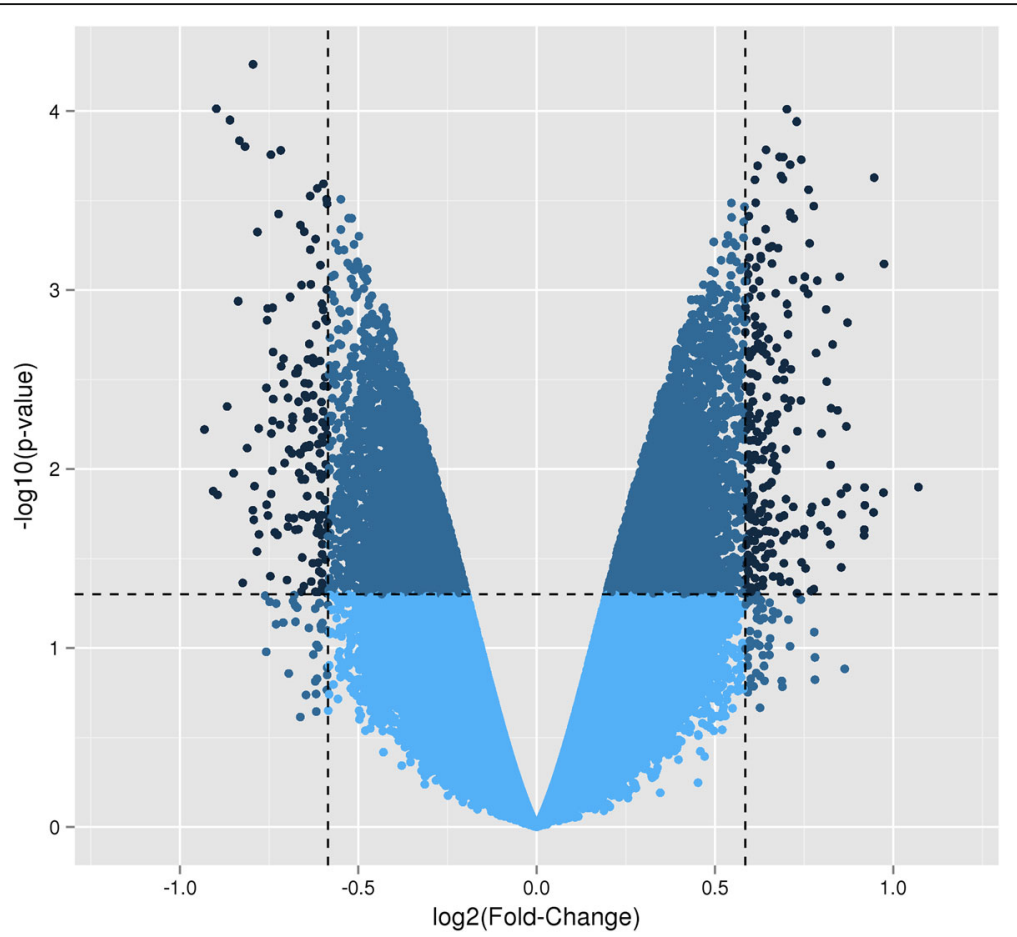

Fig. 1 Volcano plot of the DNA methylation microarray results in blastocysts originating from HIGH COMBl-exposed oocytes versus blastocysts originating from BASAL-exposed oocytes. The dots located at the left upper corner are significantly hypomethylated probes $(n=155)$; whereas, the dots located at the right upper corner are significantly hypermethylated probes $(n=240)$ at $P<0.05$ and fold change $>1.5$

is presented in Fig. 2. The proximal promoter, promoter and distal promoter regions were defined as the first $1 \mathrm{kbp}, 5 \mathrm{kbp}$ and $50 \mathrm{kbp}$ of the transcription start site. There appeared to be a tendency to conserve DNA methylation within proximal promoters, exonic regions and distal promoters. Conversely, differential DNA methylation was more likely to occur at intronic and intergenic regions and promoter sites. In addition, analysis of the distance of probes relative to CpG islands was performed. The probes were categorized into $\mathrm{CpG}$ shores, $\mathrm{CpG}$ shelfs and open seas when they were located 1-2 kbp, 2-4 kbp or $>4 \mathrm{kbp}$ away from the nearest $\mathrm{CpG}$ island, respectively. Differentially methylated regions were found in $\mathrm{CpG}$ shores, $\mathrm{CpG}$ shelfs and open seas in the HIGH COMBI group. DNA Methylation at CpG islands tended to be more stable and was not observed to be affected by high concentrations of NEFAs during oocyte maturation.

Among the loci that were differentially methylated between embryos from HIGH COMBI-treated and BASAL-treated oocytes, 148 hypermethylated and 120 hypomethylated regions mapped to coding-regions and were used for further analysis using IPA. Output from IPA analyses revealed that these coding-regions were associated with cellular development and function, metabolism, cell cycle, cell survival and death and gene expression (see Fig. 3). When applying a Benjamini-
Hochberg correction, no differentially methylated regions displayed an adjusted $P$-value $<0.05$ when comparing treatments.

The DNA methylation patterns were integrated with the transcriptome data reported by Van Hoeck et al. [5] to determine possible associations. In order to obtain a general overview of pathways affected on transcriptome and methylome level, microarray data without FDR correction were used for IPA analysis. In summary, transcriptomic comparison between blastocysts originating from oocytes matured under HIGH COMBI conditions compared to BASAL conditions revealed that 190 genes were differently expressed of which 85 up- and 105 down-regulated genes. These data were validated using qRT-PCR. The correlation between specific differentially methylated loci and expressed genes is presented in Table 3.

\section{Part 1C. Targeted analysis of DNA methylation}

Methylation profiles of specific genes of interest were evaluated using pyrosequencing techniques in embryos from HIGH COMBI-treated and BASAL-treated oocytes. The selected genes (COL6A3, APAF1, RFC4, PLSCR3, ELOVL1 and $T B K B P 1)$ are associated with pathways such as apoptosis, metabolism, gene transcription and inflammatory response. In addition, DNA methylation at two imprinted genes, $H 19$ and $S N R P N$, was also determined in embryos 


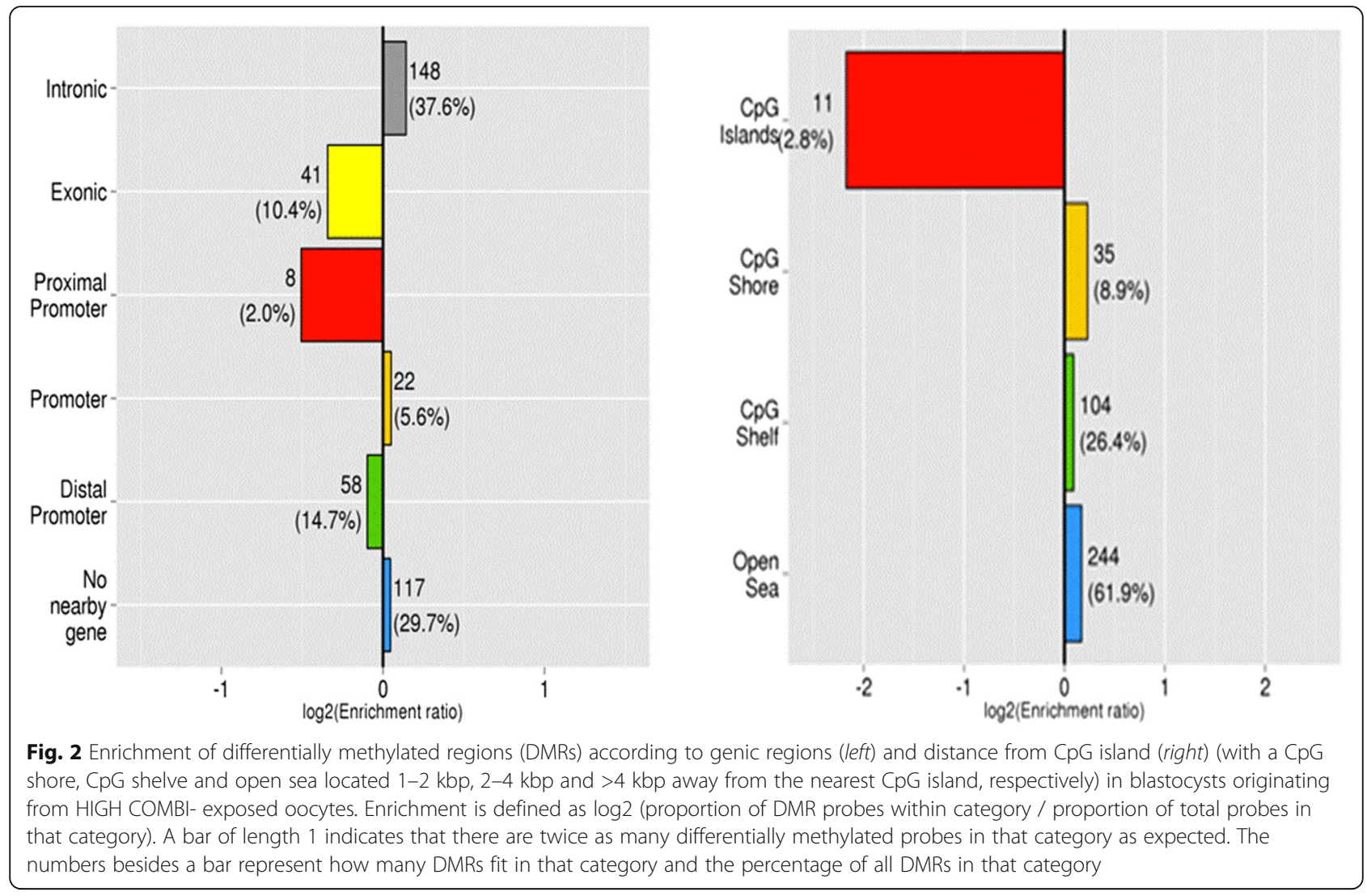

derived from HGH COMBI- and BASAL-treated oocytes. The degree of DNA methylation of these imprinted genes is known and therefore, they were implemented as controls (see Fig. 4).

Methylation at the two imprinted genes (SNRPN and H19) was not significantly different between embryos from BASAL- and HIGH COMBI-exposed oocytes (28.0\% compared to $29.0 \%$ for SNRPN and $24.8 \%$ compared to $29.9 \%$ for $H 19)$. Only APAF1 $(P=0.40)$ and, to a lesser extent, RFC4 $(P=0.20)$ showed hypermethylation (not statistically significant) in embryos from HIGH COMBItreated as compared to embryos from BASAL-treated

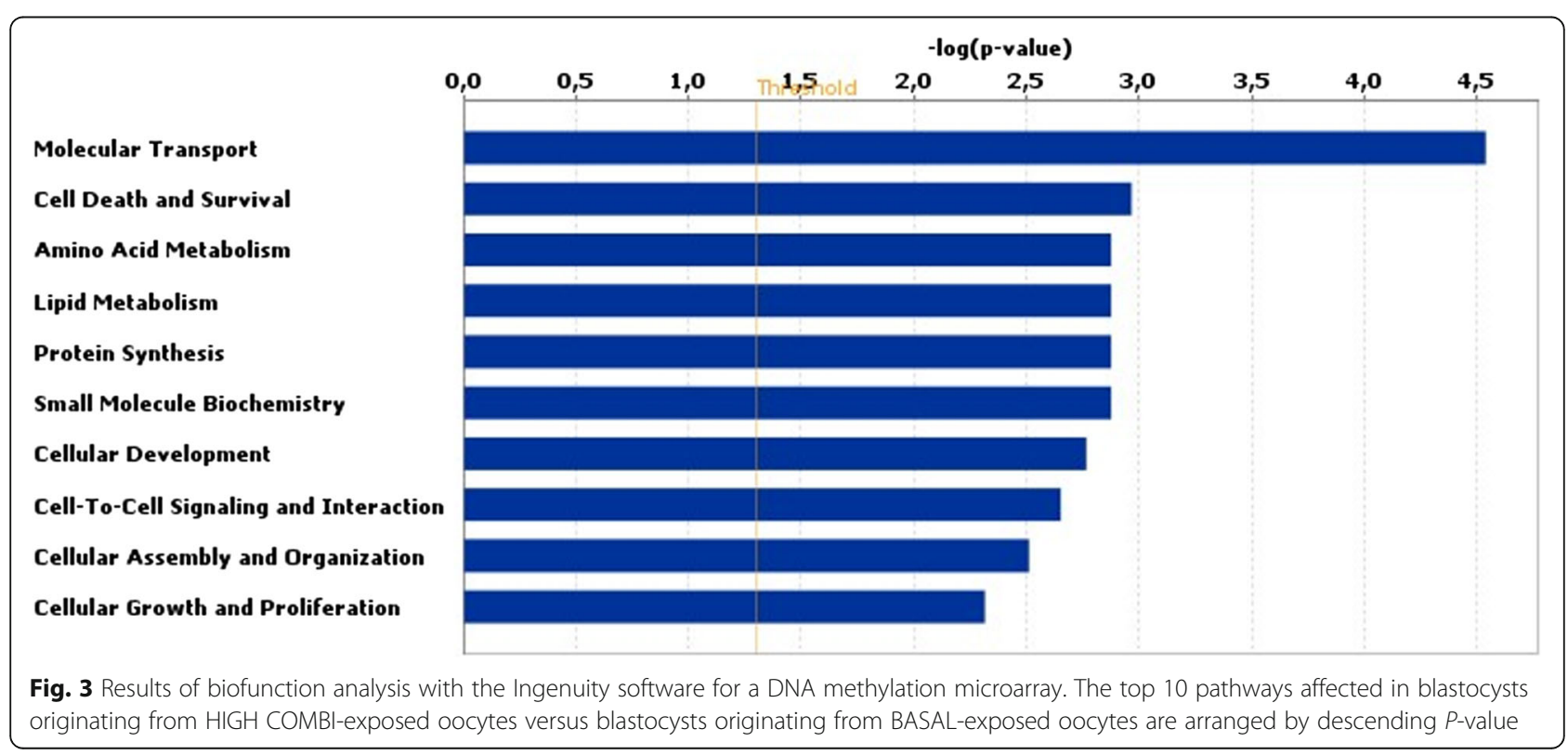


Table 3 Relation between differentially methylated genes and downstream expressed genes of blastocysts originating from oocytes exposed to high NEFA concentrations

\begin{tabular}{lll}
\hline Associated pathways & Differentially methylated genes & Downstream differentially expressed genes \\
\hline Apoptosis & TP53 & SIRT1, MAD2L1, FAM3C, CDC7, CD47, HERC5, HSPD1,SCP2, UBL3, ID3 \\
Embryo implantation & LIF & GPCPD1, CYP11A1 \\
Gene transcription & CTBP1 & SIRT 1 \\
IGF1R & PDCD10, SCP2, KRT19, CYP11A1 \\
Immune response & TCR & HERC5, HSPD1, GBP4, ID3 \\
Metabolism & RXRB & CCL17 \\
& G6PC & CYP11A1 \\
& LEP & SC4MOL, SCP2, TIMP1 \\
& PEPCK & $C Y P 11 A 1$ \\
\hline
\end{tabular}

oocytes as was observed in the microarray results, while none of the hypomethylated genes (based on the microarray results) could be validated using pyrosequencing.

Experiment 2. Blastocysts originating from NEFA-exposed embryos: consequences on gene expression and DNA methylation signatures

Part 2A. Developmental competence of blastocysts originating from NEFA-exposed embryos

Cleavage rates of embryos cultured under HIGH COMBI conditions $(65.2 \%)$ were significantly different compared to BASAL conditions $(75.6 \%)(P<0.05)$. Moreover, exposing embryos to HIGH COMBI conditions resulted in a significant reduction of the proportion of embryos reaching the blastocyst stage at day 7.5 p.i. (18.2\%) compared to BASAL-exposed oocytes $(25.3 \%)(P<0.05)$. There was also a significantly lower capacity of cleaved zygotes to develop to the blastocyst stage in the HIGH COMBI group (27.9\%) compared to the BASAL group $(33.5 \%)(P<0.05)$. Data on developmental competence are presented in Table 4.

Part 2B. Consequences for expression patterns of genes involved in epigenetic pathways using microarray approach The microarray platform identified 311 differentially expressed genes $(P<0.05$ and fold change $>1.5)$ between blastocysts originating from embryos cultured under $\mathrm{HIGH}$ COMBI and BASAL conditions. More specifically, 206 genes were up-regulated; whereas, 105 genes were downregulated (see Fig. 5). To validate the results of the microarray with an independent analysis, we used qRT-PCR (as described by Van Hoeck et al. [5]) to examine a

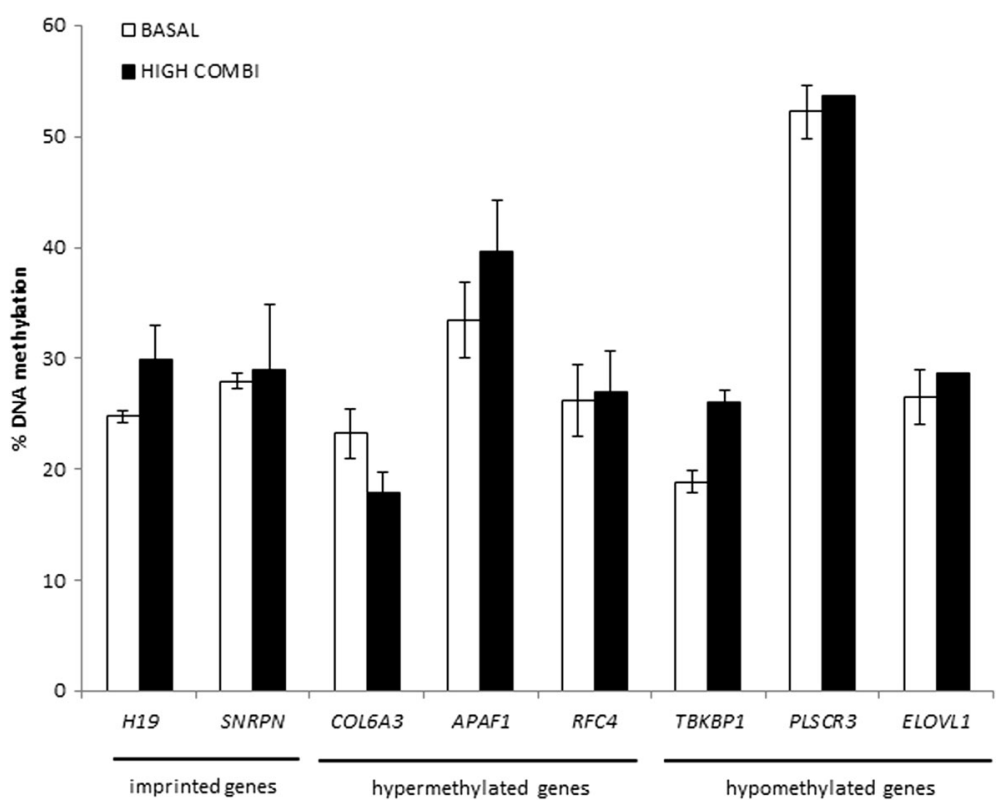

Fig. 4 Methylation patterns of H19, SNRPN, COL6A3, APAF1, RFC4, PLSCR3, ELOVL1 and TBKBP1 in blastocysts originating from HIGH COMBI-exposed oocytes versus blastocysts originating from BASAL-exposed oocytes. Bars are presented as means \pm SEM 
Table 4 Developmental competence of bovine embryos exposed to elevated NEFA concentrations during 6.5 days of in vitro culture

\begin{tabular}{lll}
\hline $\mathrm{n} \mathrm{( \% )}$ & BASAL & HIGH COMBI \\
\hline Oocytes & 1217 & 1199 \\
Cleaved & $920(75.6)^{\mathrm{a}}$ & $782(65.2)^{\mathrm{b}}$ \\
Blastocysts from oocytes matured & $308(25.3)^{\mathrm{a}}$ & $218(18.2)^{\mathrm{b}}$ \\
Blastocysts from cleaved zygotes & $308(33.5)^{\mathrm{a}}$ & $218(27.9)^{\mathrm{b}}$ \\
\hline
\end{tabular}

Data indicated with different letters (ab) per row are significantly different $(P<0.05)$

subset of 5 genes from the differentially regulated gene list. The pattern of 4 of the transcripts mirrored that seen on the arrays in terms of the direction of the change (up- or down-regulated).

IPA analysis indicated that the following networks were affected by the HIGH COMBI treatment during embryo culture; cell morphology, cell-to-cell signaling and interaction, hematological system development and function, lipid metabolism, small molecule biochemistry, vitamin and mineral metabolism, lipid metabolism and molecular transport (see Fig. 6).

Based on the transcriptomic patterns of blastocysts originating from $\mathrm{HIGH}$ COMBI-treated embryos relative to blastocysts originating from BASAL-treated embryos, changes in only a single gene associated with epigenetic modifications was identified, SHMT1. SHMT1 was downregulated in blastocysts that were cultured under HIGH COMBI conditions $(P<0.001$ and fold change $=-1.892)$.

\section{Part 2C. Assessment of DNA methylation patterns using EDMA} Comparison of the methylome profile between blastocysts, originating from embryos cultured under $\mathrm{HIGH}$ COMBI and those cultured under BASAL conditions, indicated that 4,671 loci were differentially methylated $(P<0.05$ and fold change $>1.5)$. Results are summarised in Fig. 7. More specifically, 1,912 loci were hypermethylated in HIGH COMBI as compared to BASAL embryos; whereas, DNA methylation of 2,759 loci was significantly lower in HIGH COMBI as compared to BASAL treated embryos.

Enrichment analysis of the data also determined which genomic features were present following exposure of the developing embryo for HIGH COMBI conditions and this is presented in Fig. 8. There was again a tendency to changes in methylation at intronic or intergenic regions. The level of methylation at promoter sites and exonic regions was not affected by the HIGH COMBI treatment. The distance of DMRs to CpG islands was determined as described above. DMRs were found in $\mathrm{CpG}$ shores, $\mathrm{CpG}$

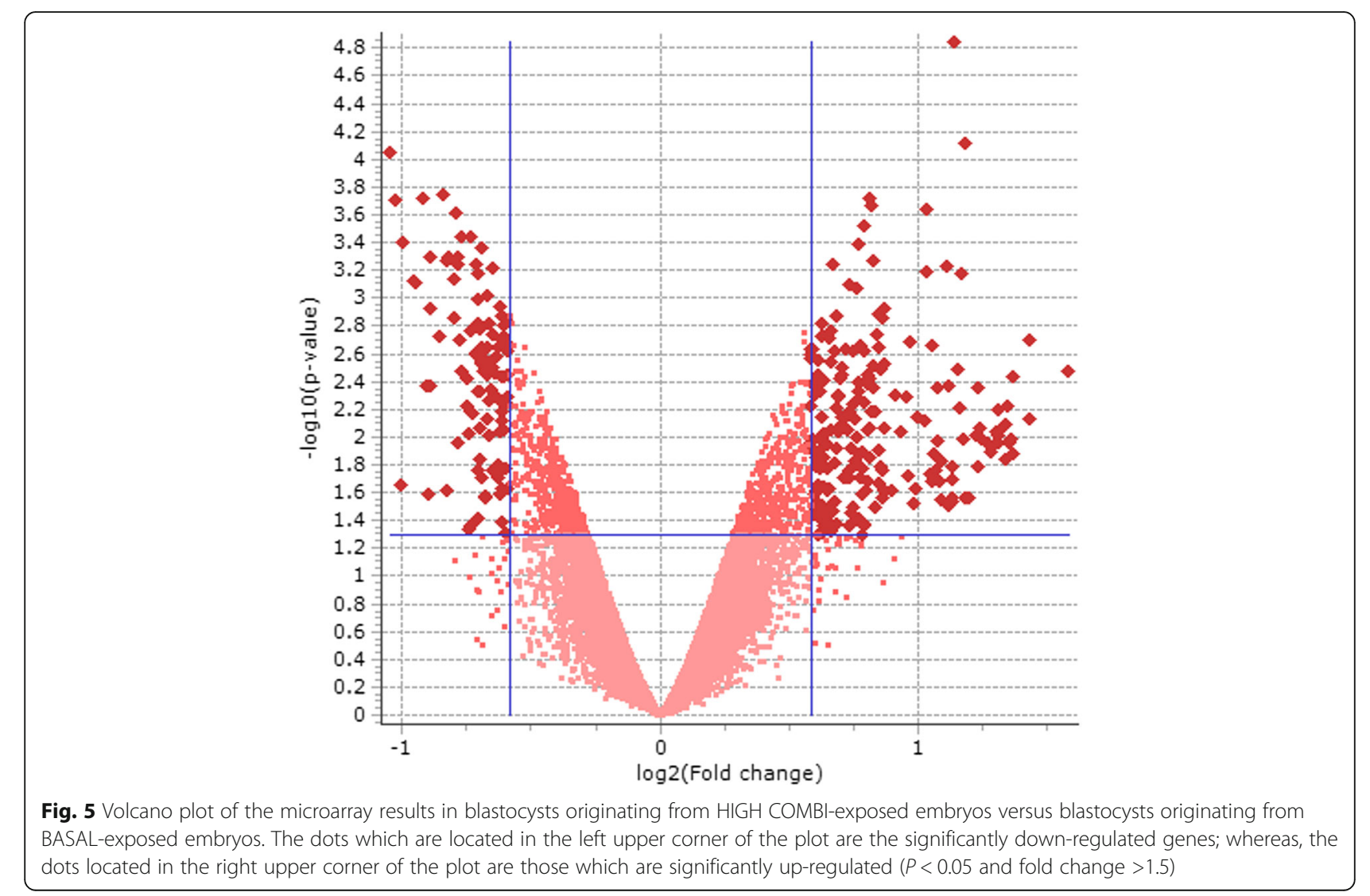




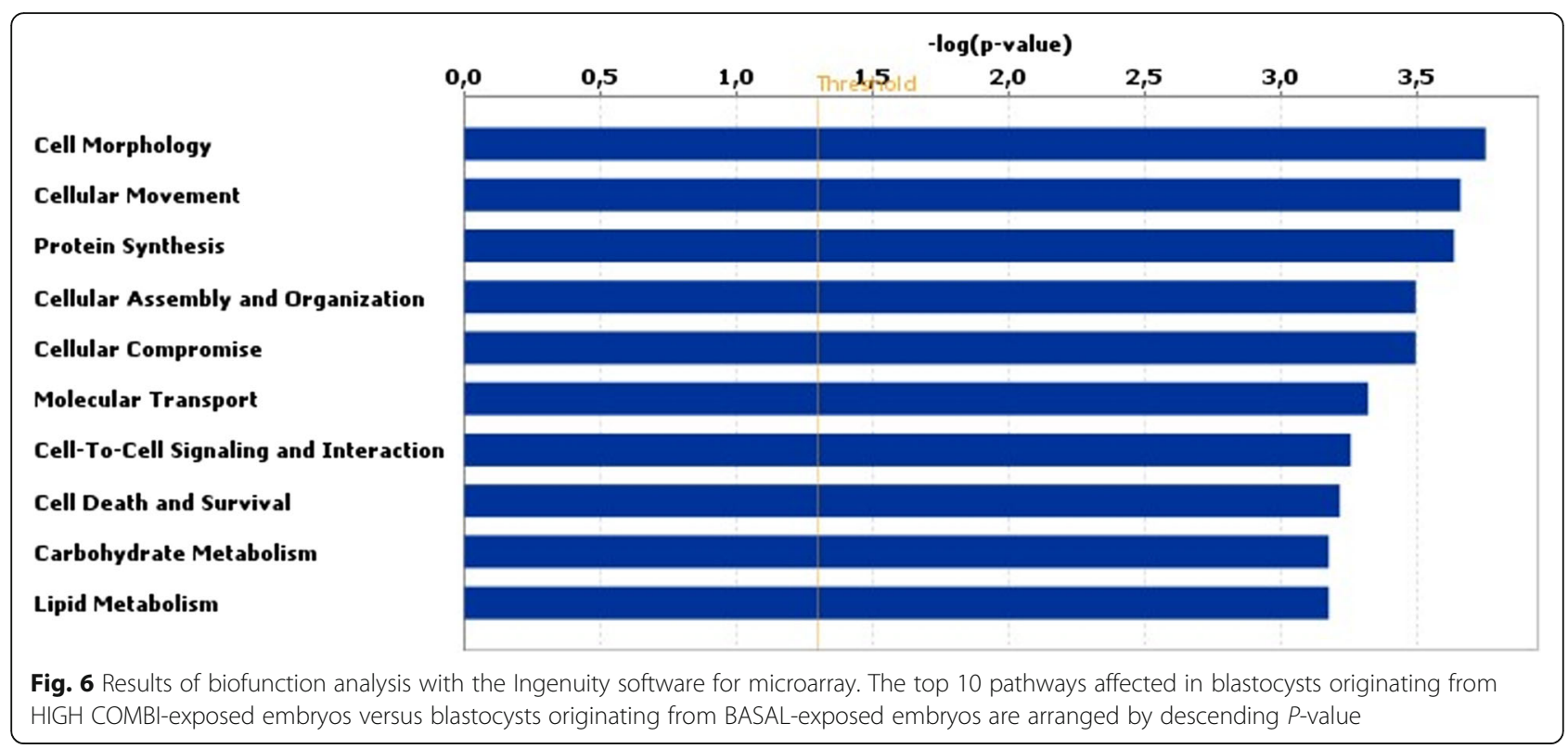

shelves and open seas. Methylation at CpG islands tended to be conserved.

Of the loci that were differentially methylated between HIGH COMBI and BASAL embryos, 1576 mapped to coding-regions and were used for subsequent pathway analysis. Of these, 697 were hypermethylated and 879 were hypomethylated. Using these genes as input for IPA it was determined that the main molecular and cellular functions altered were overall related to cellular development and function, metabolism, cell cycle, cell death and survival and gene expression (see Fig. 9). When applying a Benjamini-Hochberg correction, no differentially methylated regions had an adjusted $P$-value $<0.05$ when comparing treatments.

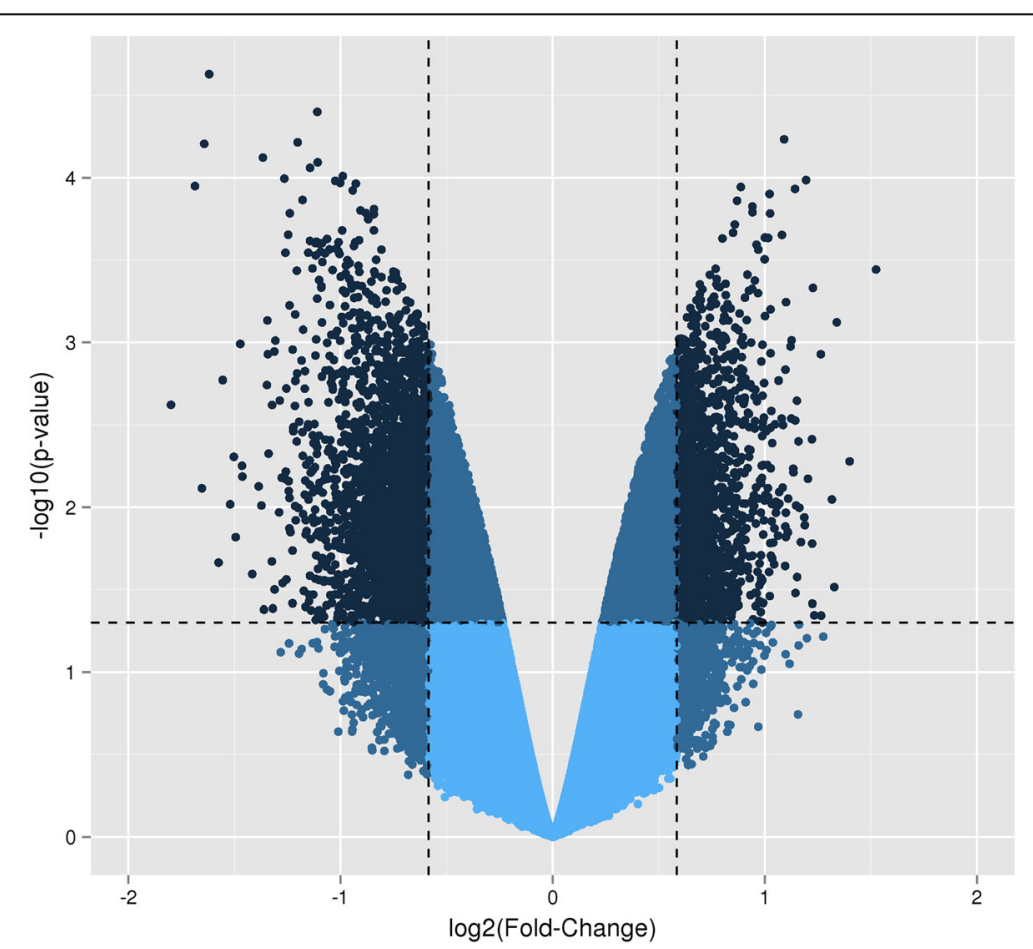

Fig. 7 Volcano plot of the microarray results in blastocysts originating from HIGH COMBl-exposed embryos versus blastocysts originating from BASAL-exposed embryos. The dots located in the left upper corner are statistically significantly hypomethylated probes $(n=879)$; whereas, the dots located in the right upper corner are statistically significantly hypermethylated probes $(n=697)(P<0.05$ and fold change $>1.5)$ 


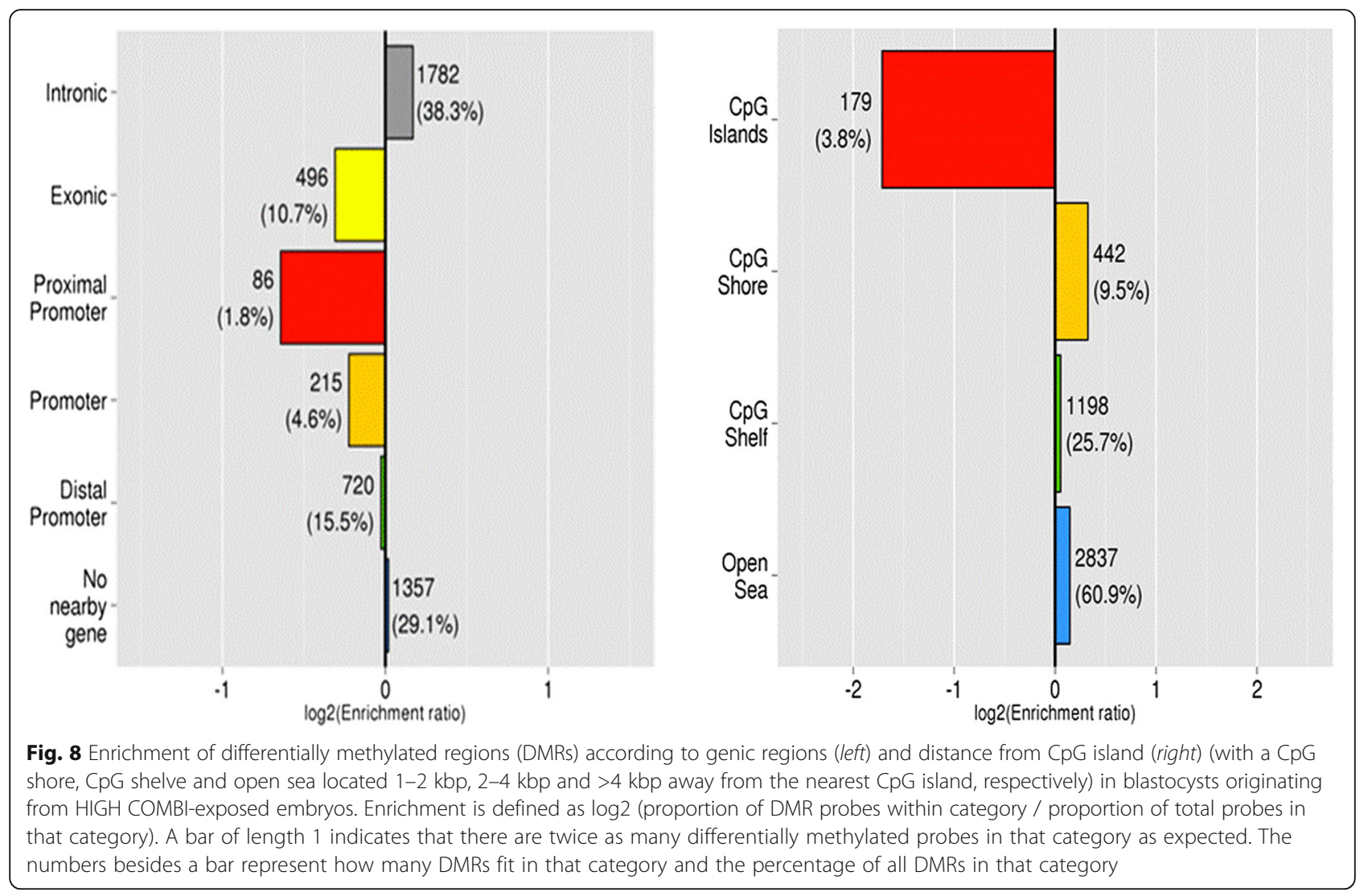

The DNA methylation data were compared with transcriptome profiles to investigate a possible association between changes in DNA methylation and gene expression. In order to maximize visualization of similar affected pathways, microarray data before FDR correction were applied for IPA analysis. The latter information is not used to draw conclusions at individual gene level. The correlation between specific differentially methylated loci and expressed genes is presented in Table 5.

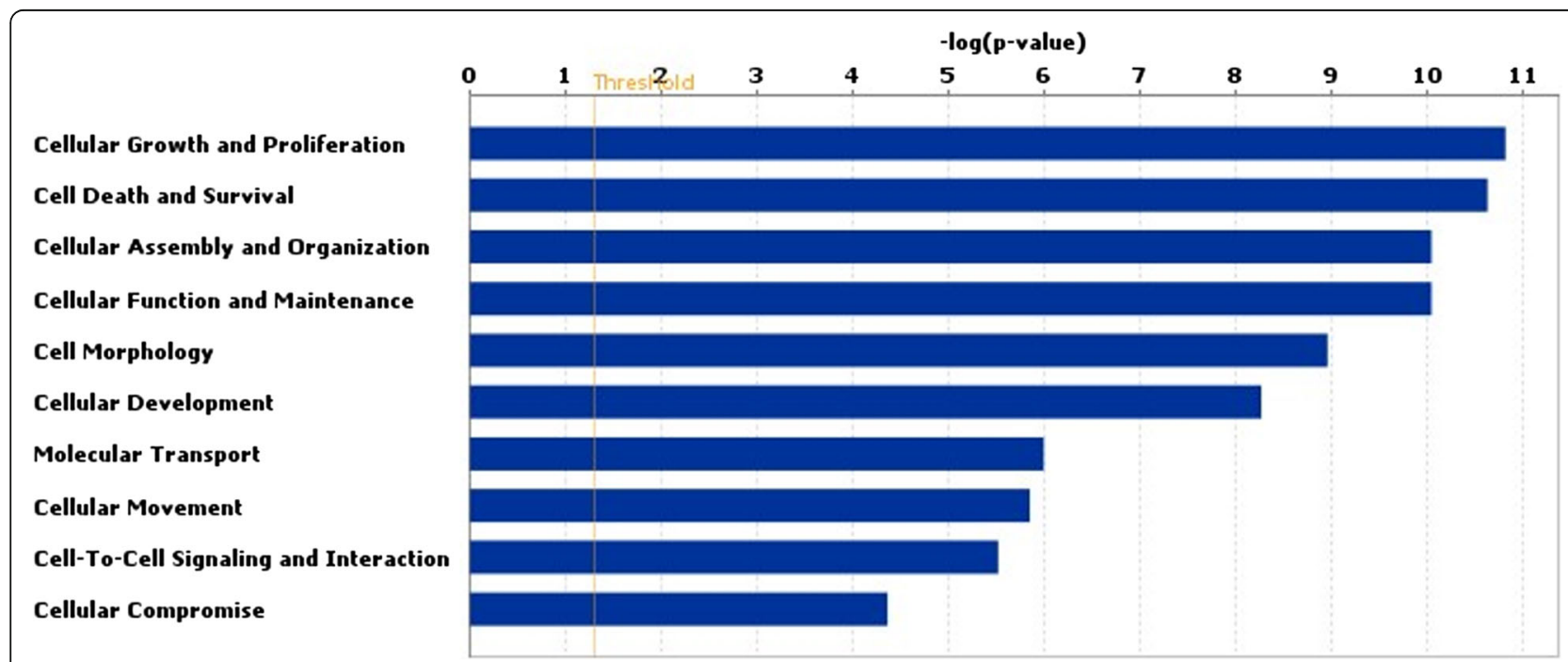

Fig. 9 Results of biofunction analysis with the Ingenuity software for a DNA methylation microarray. The top 10 pathways affected in blastocysts originating from $\mathrm{HIGH}$ COMBI-exposed embryos versus blastocysts originating from BASAL-exposed embryos are arranged by descending $P$-value 
Table 5 Relation between differentially methylated genes and downstream expressed genes of blastocysts originating from embryos exposed to high NEFA concentrations

\begin{tabular}{|c|c|c|}
\hline Associated pathways & Differentially methylated genes & Downstream differentially expressed genes \\
\hline Apoptosis & TP53 & $\begin{array}{l}\text { SERPINE1, DCTN2, CNN3, BHLHB2, MTDH, ASNS, GLB1, CNN1, HMGCS1, } \\
\text { CCND2, LBR, ANKH, NANOG, SEC61B, HSPG2, COX7A2, GZMB, IGFBP7 }\end{array}$ \\
\hline Autophagy & ATG16L1 & UPK1A \\
\hline Cell cycle & TERF2 & GLB1 \\
\hline Cell differentiation & FGFR2 & CCND2, NANOG, NR5A2 \\
\hline Cell interaction & Alpha catenin & RHOC, IGFBP7, TWIST2 \\
\hline \multirow[t]{2}{*}{ Cell signaling } & $E R K 1 / 2$ & SERPINE1, CCND2, LDLR, NANOG, RHOC \\
\hline & ITGAV & SERPINE1, LDLR \\
\hline Cell survival & FGF10 & $S C D, L D L R, L F N G$ \\
\hline Cellular development & THPO & CCND2, GP1BA \\
\hline \multirow[t]{3}{*}{ Hormonal regulation } & estrogen receptor & SERPINE1, CCND2, LDLR, MUC1 \\
\hline & FSH & SERPINE1, CCND2, LDLR, AQP3, ARL4C, GZMB, CARD10, DUSP14, GATA4 \\
\hline & FSHR & GATA4, GZMBA \\
\hline \multirow[t]{3}{*}{ Immune response } & CD28 & TOM1L1, CCND2, TXNRD1, PA2G4, AQP3, SEC61B, RHOC, GZMB, DUSP14 \\
\hline & $\mathrm{Cg}$ & BHLHB2, CCND2, LDLR, S100A10, NR5A2, GATA4 \\
\hline & $T C R$ & $\angle B R, P A 2 G 4, G Z M B, A R P P 21, L M N B 1$ \\
\hline Ion transport & WNK1 & SERPINE1 \\
\hline \multirow[t]{3}{*}{ Gene transcription } & Creb & MIF, HSPB8, LDLR, ELL \\
\hline & PRDM16 & SERPINE1 \\
\hline & SMARCA4 & SERPINE1, MUC1, ASNS, FLNB, TXNRD1, ARL4C \\
\hline
\end{tabular}

\section{Part 2D. Targeted analysis of DNA methylation}

In order to re-evaluate the DNA methylation microarray results, we investigated the methylation profiles of ERCC1, CELF2, ZFAND6, PREX1, APPL2 and GCLC in HIGH COMBI and BASAL embryos using pyrosequencing. The average methylation level at two imprinted gene DMRs, H19 and SNRPN, was also determined in both BASAL and HIGH COMBI embryos as controls. The average methylation level of the selected genes of $\mathrm{HIGH}$ COMBI- compared to BASAL-treated embryos is presented in Fig. 10.

SNRPN had an average methylation level of $28.1 \%$ in BASAL embryos compared to $31.5 \%$ in HIGH COMBI embryos. For the H19 DMR, similar methylation levels were observed in BASAL (22.8\%) and HIGH COMBI (25.8\%) embryos. ERCC1 $(P=0.16)$, CELF2 $(P=0.52)$ and ZFAND6 $(P=0.81)$ showed hypermethylation in HIGH COMBI embryos compared to control embryos as was observed in the microarray results (not statistically significant). Hypomethylation of HIGH COMBI embryos compared to BASAL embryos was also observed for APPL2 $(P=0.45)$ (not statistically significant).

\section{Discussion}

It has been shown previously that elevated NEFA concentrations, as present in several metabolic disorders, can impair oocyte and embryo developmental competence and influence transcriptomic and phenotypic fingerprints of resultant blastocysts [5, 7]. Here, we provide evidence that alterations to the epigenome occur in response to conditions of elevated NEFA concentrations during oocyte maturation or early embryo culture. Major affected pathways are related to cell death and survival, immunity, metabolism and metabolic disorders. Although interpretation of methylation rates at individual loci remained difficult as high rates of variation were observed in methylation patterns between blastocysts within treatment groups, the data shed a clear light on the heatmap of pathways affected by an adverse environment. These epigenetic changes may contribute to the observed transcriptomic and phenotypic alterations and could persist during further development.

Following exposure of oocytes to pathophysiological concentrations of NEFAs, the main pathways affected at the transcriptomic level in blastocysts were related to lipid and carbohydrate metabolism, small molecule biochemistry and cellular development as described by Van Hoeck et al. [5]. Furthermore, transcriptomic dataanalysis revealed that NEFA exposure during oocyte maturation affected the expression of genes related to epigenetic programming; HIST1H2BN, UBA2 and PPP1CB. For example, HIST1H2BN encodes a histone that is a member of the histone $\mathrm{H} 2 \mathrm{~B}$ family and functions in the compaction of chromatin and thus in histone 


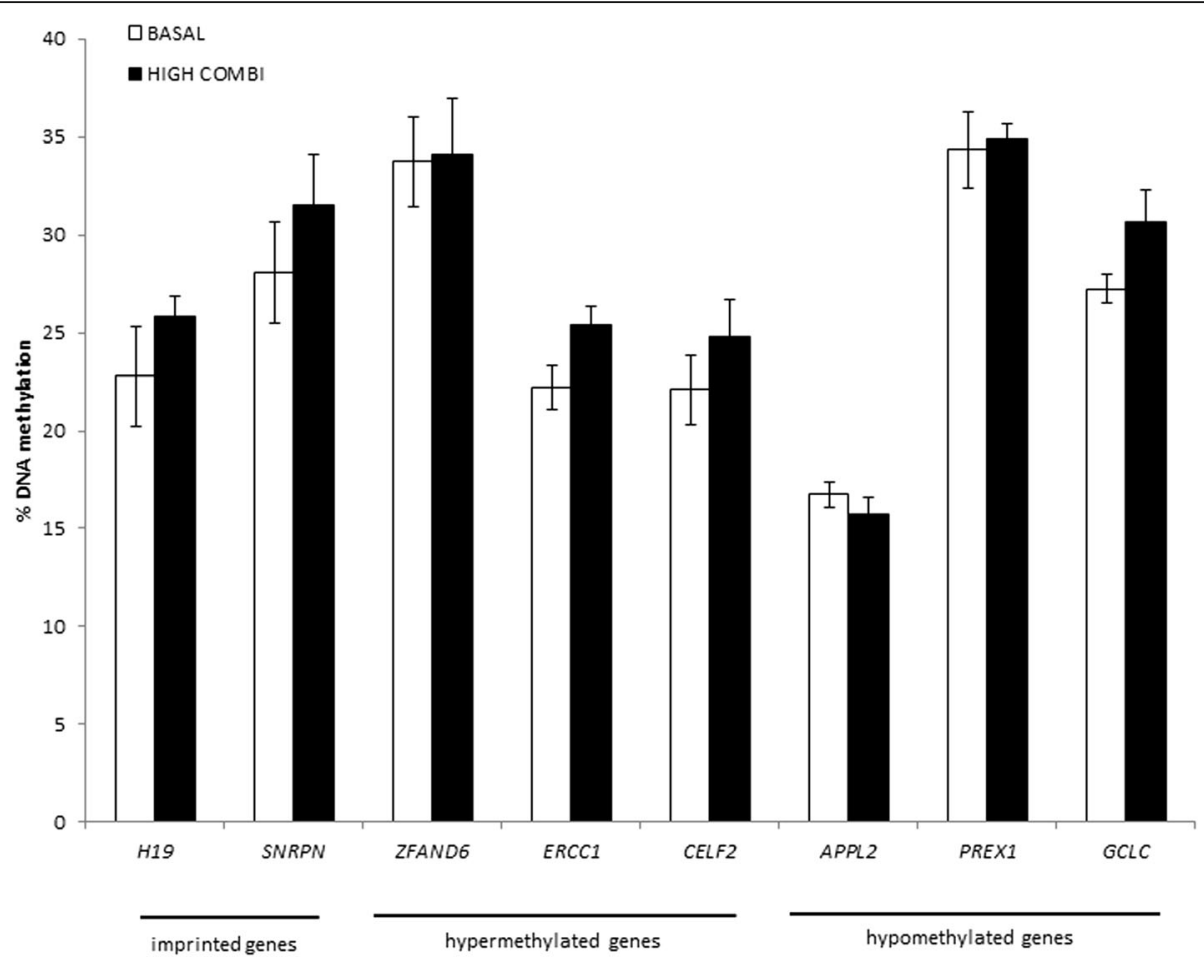

Fig. 10 Methylation patterns of ERCC1, CELF2, ZFAND6, PREX1, APPL2 and GCLC in blastocysts originating from HIGH COMBI-exposed embryos versus blastocysts originating from BASAL-exposed embryos. Bars are presented as means \pm SEM

modifications [33]. Such histone modifications in fetal primates have been previously linked to conditions of maternal overnutrition [34]. Therefore, we assumed that high NEFA concentrations, associated with maternal metabolic disorders, also impact on epigenetic mechanisms.

Genome-wide analysis revealed that elevated NEFAs during oocyte maturation influenced overall DNA methylation patterns in the resultant blastocysts, affecting many DMRs associated with cell death and survival and cellular metabolism. Aberrant DNA methylation patterns were observed in pathways related to caspase activation, p53induced apoptosis, Ras-signalling and Wnt-signalling. The latter observations are in line with the phenotypic data published by Van Hoeck et al. [4], reporting an increased apoptotic cell ratio in blastocysts from HIGH COMBI- as compared to BASAL-exposed oocytes. Previously, Ge et al. [35] demonstrated an association between maternal metabolic disorders and epigenetic regulation of oocyte metabolism in mice. Similarly, our data revealed methylation changes in lipid transfer and synthesis pathways in blastocysts originating from HIGH COMBI-exposed oocytes. Similar transcriptome and phenotypic fingerprints of blastocysts originating from HIGH COMBI-exposed oocytes were previously described [5, 7]. Epigenetic alterations were also observed in pathological processes such as obesity and insulin-dependent diabetes. These alterations in insulin signalling are interesting since an excessive uptake and accumulation of fatty acids in somatic cell lines is known to be closely associated with type II-diabetes [36], as for example shown in muscle cells by Bilan et al. [37]. Furthermore, Van Hoeck et al. $[4,5]$ observed phenotypic features associated with glucose intolerance in blastocysts originating from HIGH COMBI-exposed oocytes.

Following exposure of developing embryos to elevated NEFA concentrations during culture, the main pathways affected in resultant blastocysts using transcriptomic analysis were similar to those in the IVM experiment, i.e. lipid and carbohydrate metabolism, small molecule biochemistry and cellular development. Down-regulation of genes related to embryonic cell growth, cell differentiation and cell-cell interaction suggests a reduced developmental competence of blastocysts from HIGH COMBI-treated embryos. Interestingly, HIGH COMBI exposure during embryo culture also affected the expression of a gene required for DNA synthesis and methylation, SHMT1. Down-regulation of SHMT1 has previously been shown to increase methionine formation and thus might affect DNA methylation [38]. Overall changes in DNA methylation were indeed observed in blastocysts from HIGH COMBI-exposed embryos.

DNA methylation analysis of blastocysts originating from HIGH COMBI-exposed embryos revealed altered 
methylation at loci of genes related to pathways associated with apoptosis, such as the Ras/MAPK signalling [39], the formation of antioxidants [40] and mitochondrial dysfunction [41]. 'Molecular transport' pathways, for example involved in regulation of endosomal cholesterol trafficking by recycling sterol carrier proteins, were significantly affected [42]. Overall lipid metabolism was affected by high NEFA exposure with particular focus on pathways as adipogenesis, adipocyte differentiation and fatty acid synthesis [43]. Exposure of embryos to high NEFA concentrations not only influenced lipid but also glucose metabolism, as for example observed in glucose transport [44-46]. Some metabolism- or immune response-related genes are also associated with obesity and insulin resistance [41, 47-50]. Alterations in these pathways may further affect the offspring since maternal metabolic disorders have been shown to increase the risk of developing metabolic disorders in the offspring [51].

Even though the aim of the present study was to achieve a broad overview of affected pathways, an attempt was made to verify DNA methylation at gene level in both IVM and IVC experiments by three different approaches.

Validation of EDMA array data using other techniques has been proven difficult due to the non-linear amplification steps involved in array generation. Shojaei et al. [32] have shown that pyrosequencing offers a partial solution to this problem, whereby methylation trends (gain or loss) generally replicate. Therefore, we chose this technique in the first approach to validate the array. Only two and four of the six genes showed a similar trend in methylation direction as observed with the microarray in the IVM and IVC experiment, respectively. None of these differences were statistically significant due to the high variability and thus pyrosequencing could not confirm the microarray results. In this context, such a high level of variation in average methylation between replicates in bovine day 7 blastocysts has also been observed by O'Doherty and McGettigan [12]. The latter authors suggested that the observed variability in DNA methylation at day 7 may be due to preferential amplification of maternal or paternal alleles, overrepresentation of DNA from the ICM or the TE or differences between gender. This variation in DNA methylation between blastocysts was previously described by Dobbs et al. [17].

In the second approach, gene-specific methylation was assessed by applying an FDR correction to the microarray data. The digestion protocol targets specific cytosines that are not necessarily alone in the methylation landscape creating a bias towards the analysis of these sites compared to all sites [32]. In the context of relatively small individual changes for any specific DMR, the power obtained is not sufficient to create a list of defined targets. Therefore, a Benjamini-Hochberg correction was applied to the list of DMRs to adjust for the number of targets. No DMRs remained when the stringency was raised to the maximum, indicating that the differences due to the NEFA treatment were minimal at gene level. Additionally, this test is highly sensitive to the number of biological replicates [52] and the present study used, due to practical limitations, four biological replicates. Bioinformatic tools, such as IPA, are consequently required to identify if the distribution of the hundreds of DMRs is random or associated with specific functions of pathways. Analysis of the DMR lists with the IPA software unraveled significant changes in multiple pathways due to NEFA exposure as explained above.

In the last approach, methylome data were compared with transcriptome data to examine if genes displayed changes in both DNA methylation and gene expression signatures. It is generally accepted that methylation is implied in expressing/silencing of the gene [53]. However, no differentially methylated loci did result in modified gene expression patterns. This discrepancy between methylation and expression was also observed by Salilew-Wondim et al. [54] who suggested that changes in DNA methylation could not only result in modifications of mRNA expression but also alter the expression of other non-coding RNAs. Moreover, epigenetic regulation of gene expression is complex and also involves additional epigenetic mechanisms like histone modifications [33]. Besides the discrepancy of transcriptome and methylome changes of individual genes, comparable changes were observed at the level of pathways. In this context, IPA analysis confirmed an overlap between pathways displaying altered gene expression and DNA methylation and thus suggests that DNA methylation is an epigenetic trigger for changes in gene expression due to elevated NEFA exposure.

Based on the lack of validation using these different approaches, we conclude that in the present study the EDMA array was not able to detect changes in DNA methylation in order to draw specific conclusions at the level of an individual gene. Aside from the methodological restrictions, the blastocyst as such is a difficult target for methylation analysis. Rekik et al. [55] observed very dynamic gene expression profiles during a relatively short time period encompassing blastocyst formation and hatching. Similarly, changes in DNA methylation fingerprints emerge from fertilization onwards. DNA methylation declines as the embryo undergoes successive cell divisions to a nadir at the 6-8 cell stage and increases thereafter. At blastocyst level, DNA methylation varies depending upon gender and cell lineage as demonstrated by Dobbs et al. [17]. Even imprinted genes, which are resistant to epigenetic reprogramming, may be susceptible to instability at the blastocyst stage [56]. We tried to minimize these effects by pooling embryos of similar stages across treatments and replicates to generate comparable biological replicates 
although the extent of DNA methylation still remains naturally variable among samples of similar origin. Notwithstanding these limitations, the blastocyst is an interesting target to investigate. Transcriptome studies have extensively shown how early embryos interact with their immediate microenvironment $[31,57,58]$. Epigenetic reprogramming at this stage puts the embryo at risk of programming errors with potential long-term consequences due to an adverse environment [23].

Comparison of data from NEFA exposure during IVM $(24 \mathrm{~h})$ and IVC (168 h) demonstrated that a higher number of differentially expressed genes and aberrantly methylated loci were present in response to elevated NEFA concentrations during IVC compared to IVM. All data regarding changes in DNA methylation, gene expression profile and associated affected canonical pathways in the IVM and IVC experiment are summarized in Fig. 11. Indeed, it is likely that oocytes are less sensitive to NEFA exposure than embryos due to the presence of the surrounding cumulus cells. It has been observed that the cumulus cells incorporate fatty acids as lipids and thereby protect the oocyte from in vitro induced lipotoxic effects $[59,60]$. Moreover, oocytes rely on oxidative fatty acid metabolism during final maturation [61]. Embryos, however, use pyruvate and glucose as energy sources [62]. This change in energy source during development could contribute to the smaller effect of NEFA exposure observed during oocyte maturation as compared to embryo culture. The window of exposure may also determine the extent of DNA methylation dysregulation and regulation of gene expression. DNA methylation increases during oocyte growth and these marks are erased shortly after fertilization, which could provide an opportunity to compensate for aberrant DNA methylation incurred during IVM. This could account for the lower number of differentially methylated loci noticed in blastocysts derived from NEFA-exposed oocytes, compared to blastocysts derived from NEFA-exposed embryos. Salilew-Wondim et al. [54] recently suggested a similar hypothesis as they observed a strong positive association between the extent

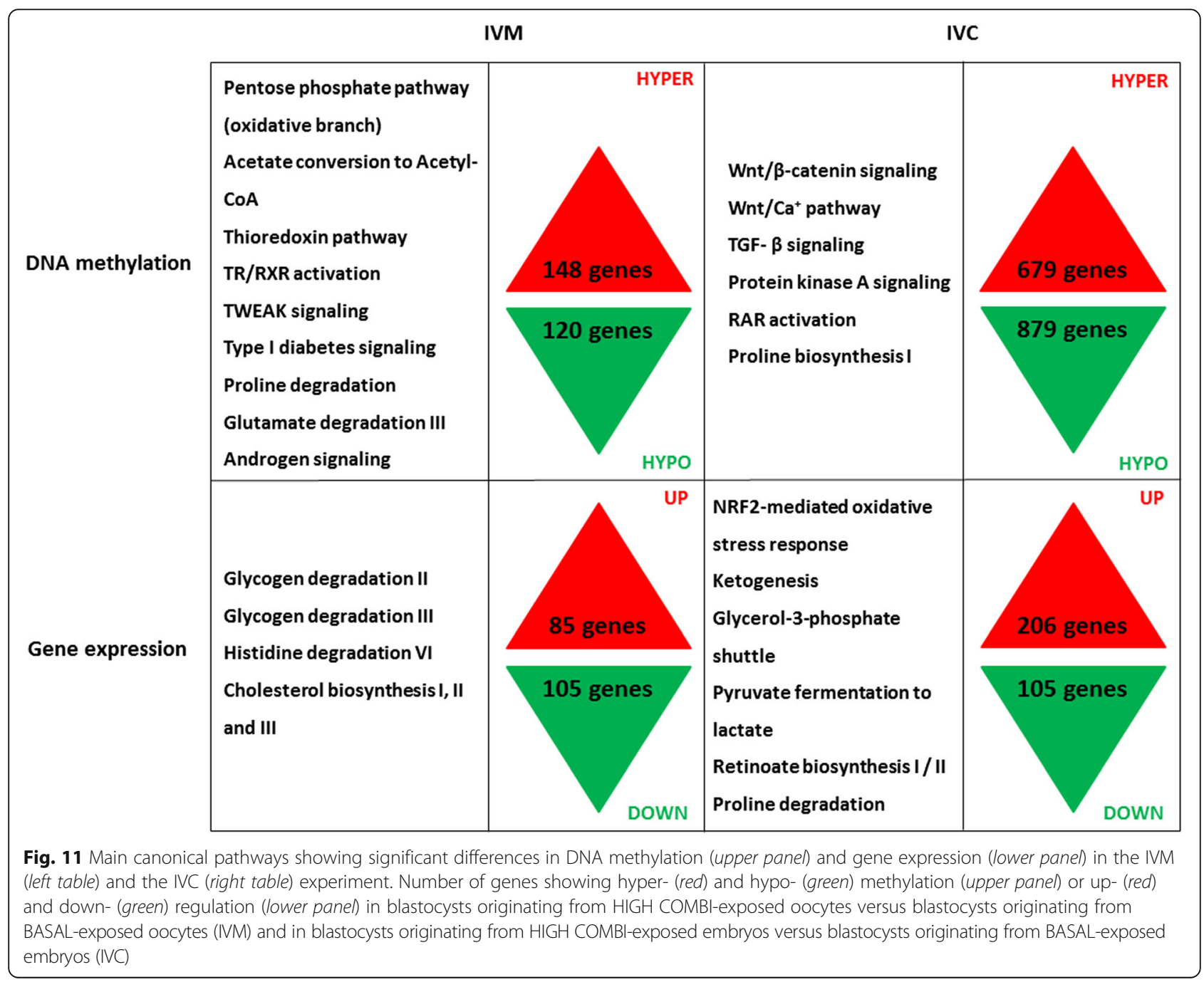


of DNA methylation dysregulation and the developmental stages completed under in vitro conditions.

Finally, the current study not only helps to unravel the window of epigenetic sensitivity for environmental changes in NEFA concentrations, but also should be integrated to see potential associations between DNA methylation, gene expression and phenotypic profiles. The correlation between canonical pathways in which genes were differentially methylated and expressed was investigated in both IVM and IVC experiments and has been presented in Fig. 11. Overall, pathways affected in both IVM and IVC experiments were mostly related to apoptosis, amino acid metabolism, lipid metabolism and carbohydrate metabolism.

\section{Conclusions}

In the present study, we were only able to acquire an overall perspective of the extent of the differences in methylation. A more in-depth assessment of DNA methylation changes at the level of individual genes was not feasible due to both methodological and biological limitations. Although the EDMA array provides a robust wholegenome view of DNA methylation in bovine early embryos, subtle alterations are not detected through multiple testing corrections. Additionally, vast epigenetic erasure and reprogramming events during early embryogenesis make this phase of development a sensitive window for perturbations. This dynamic window makes the blastocyst both an intriguing and complicated target for further research.

Elevated NEFA concentrations during either in vitro oocyte maturation or embryo development as observed in females suffering metabolic disorders associated with upregulated lipolysis, impact the resultant blastocysts' transcriptomic and epigenetic profiles. Key cellular pathways affected by NEFA exposure are similar after integration of gene expression and methylation patterns, with particular reference to lipid and carbohydrate metabolism, cell death, immune response and metabolic disorders. Furthermore, early cleavage embryos were even more susceptible to altered in vitro conditions than oocytes during maturation, as a higher level of epigenetic dysregulation was evident in the former. This information is crucial for helping to elucidate the underlying mechanisms of subfertility and development of metabolic disease in the offspring. It suggests that maternal metabolic disorders can influence epigenetic reprogramming in the embryo and affect subsequent development, potentially imprinting long-lasting marks during later stages of adult life. However, more research is necessary to investigate long-term effects of this epigenetic dysregulation.

\section{Abbreviations}

BSA: Bovine serum albumin; COCs: Cumulus oocyte complexes; DMRs: Differentially methylated regions; DOHAD: Developmental origins of adult health and disease; EDMA: EmbryoGENE DNA Methylation Array;
FDR: False discovery rate; ICM: Inner cell mass; IPA: Ingenuity Pathways Analysis; IVC: In vitro culture; IVM: In vitro maturation; mEGF: Murine epidermal growth factor; NEFA: Non-esterified fatty acid; OA: Oleic acid; PA: Palmitic acid; SA: Stearic acid; TE: Trophectoderm

\section{Acknowledgements}

The authors acknowledge Els Merckx and Silke Andries, of the Gamete Research Center, University of Antwerp, for their outstanding technical assistance with IVP and Prof. Dr. Erik Fransen, StatUa Center for Statistics, University of Antwerp, for his help with the statistical analysis.

\section{Funding}

This work was supported by the Flemish Research Fund (FWO grant 11L8716N), COST ACTION FA1201 (short mission scientific stay in CPW's lab) and Natural Science and Engineering Research Council of Canada (NSERC) as part of EmbryoGENE Network (grant NETGP 340825-06).

Availability of data and material

The datasets supporting the conclusions of this article are available in the NCBI's Gene Expression Omnibus (GEO) repository, series accession number GSE83768 (http://www.ncbi.nlm.nih.gov/geo/query/acc.cgi?acc=GSE83768).

\section{Authors' contributions}

KLJD performed bovine in vitro embryo production and was involved in carrying out microarray and pyrosequencing. DG performed the microarray analysis. EF performed bioinformatic analyses. AMOD and AT performed pyrosequencing for candidates. CPW supervised the pyrosequencing work. $J L M R L$ and PEJB supervised the overall work. KLJD, WH and JLMRL drafted the final manuscript. All authors read and approved the final manuscript.

\section{Competing interests}

The authors declares that they have no competing interests.

\section{Consent for publication}

Not applicable.

\section{Ethics approval}

This study involved the use of animal tissue. Due to the use of slaughterhouse material, no ethical approval was needed.

\section{Author details}

${ }^{1}$ Laboratory of Veterinary Physiology and Biochemistry, Department of Veterinary Sciences, Faculty of Pharmaceutical, Biomedical and Veterinary Sciences, University of Antwerp, Wilrijk, Belgium. ${ }^{2}$ Centre de Recherche en Biologie de la Reproduction (CRBR), Département des Sciences Animales, Université Laval, Québec, Canada. ${ }^{3}$ British Columbia Cancer Agency, University of British Columbia, Vancouver, Canada. ${ }^{4}$ School of Agriculture and Food Science, University College Dublin, Dublin, Ireland. ${ }^{5}$ Centre for Molecular Biosciences, School of Biomedical Sciences, University of Ulster, Coleraine, UK.

Received: 29 June 2016 Accepted: 2 December 2016

Published online: 08 December 2016

\section{References}

1. Leroy JLMR, Valckx SDM, Jordaens L, De Bie J, Desmet KL, Van Hoeck V, Britt JH, Marei WF, Bols PEJ. Nutrition and maternal metabolic health in relation to oocyte and embryo quality: critical views on what we learned from the dairy cow model. Reprod Fertil Dev. 2015;27(4):693-703.

2. Leroy JLMR, Van Soom A, Opsomer G, Bols PEJ. The consequences of metabolic changes in high-yielding dairy cows on oocyte and embryo quality. Animal. 2008;2(08):1120-7.

3. Aardema $H$, Vos PLAM, Lolicato F, Roelen BAJ, Knijn HM, Vaandrager AB, Helms JB, Gadella BM. Oleic acid prevents detrimental effects of saturated fatty acids on bovine oocyte developmental competence. Biol Reprod. $2011 ; 85(1): 62-9$

4. Van Hoeck V, Sturmey RG, Bermejo-Alvarez P, Rizos D, Gutierrez-Adan A, Leese HJ, Bols PE, Leroy JL. Elevated non-esterified fatty acid concentrations during bovine oocyte maturation compromise early embryo physiology. PLoS One. 2011;6(8):e23183. 
5. Van Hoeck V, Rizos D, Gutierrez-Adan A, Pintelon I, Jorssen E, Dufort I, Sirard MA, Verlaet A, Hermans N, Bols PE, et al. Interaction between differential gene expression profile and phenotype in bovine blastocysts originating from oocytes exposed to elevated non-esterified fatty acid concentrations. Reprod Fertil Dev. 2015;27(2):372-84.

6. O'Doherty AM, O'Gorman A, al Naib A, Brennan L, Daly E, Duffy P, Fair T. Negative energy balance affects imprint stability in oocytes recovered from postpartum dairy cows. Genomics. 2014;104(3):177-85.

7. Van Hoeck V, Leroy JL, Arias Alvarez M, Rizos D, Gutierrez-Adan A, Schnorbusch K, Bols PE, Leese HJ, Sturmey RG. Oocyte developmental failure in response to elevated nonesterified fatty acid concentrations: mechanistic insights. Reproduction. 2013;145(1):33-44.

8. Rutledge CE, Thakur A, O'Neill KM, Irwin RE, Sato S, Hata K, Walsh CP. Ontogeny, conservation and functional significance of maternally inherited DNA methylation at two classes of non-imprinted genes. Development. 2014;141(6):1313-23.

9. Uysal F, Akkoyunlu G, Ozturk S. Dynamic expression of DNA methyltransferases (DNMTs) in oocytes and early embryos. Biochimie. 2015;116:103-13.

10. Golding MC, Williamson GL, Stroud TK, Westhusin ME, Long CR. Examination of DNA Methyltransferase expression in cloned embryos reveals an essential role for Dnmt1 in bovine development. Mol Reprod Dev. 2011;78(5):306-17.

11. $M-x$ Y, X-w F, G-b Z, Y-p H, Du M, Wang L, Zhu S-e. Abnormal DNA methylation in oocytes could be associated with a decrease in reproductive potential in old mice. J Assist Reprod Genet. 2012;29(7):643-50.

12. O'Doherty AM, McGettigan PA. Epigenetic processes in the male germline. Reprod Fertil Dev. 2015;27(5):725-38.

13. O'Doherty AM, O'Shea LC, Fair T. Bovine DNA Methylation Imprints Are Established in an Oocyte Size-Specific Manner, Which Are Coordinated with the Expression of the DNMT3 Family Proteins. Biol Reprod. 2012;86(3):67.

14. Shirane K, Toh H, Kobayashi H, Miura F, Chiba H, Ito T, Kono T, Sasaki H. Mouse oocyte methylomes at base resolution reveal genome-wide accumulation of non-CpG methylation and role of DNA methyltransferases. PLoS Genet. 2013;9(4):e1003439.

15. Dean W, Santos F, Stojkovic M, Zakhartchenko V, Walter J, Wolf E, Reik W. Conservation of methylation reprogramming in mammalian development: Aberrant reprogramming in cloned embryos. Proc Natl Acad Sci U S A. 2001:98(24):13734-8.

16. Smith ZD, Chan MM, Mikkelsen TS, Gu H, Gnirke A, Regev A, Meissner A. A unique regulatory phase of DNA methylation in the early mammalian embryo. Nature. 2012;484(7394):339-44.

17. Dobbs KB, Rodriguez M, Sudano MJ, Ortega MS, Hansen PJ. Dynamics of DNA Methylation during Early Development of the Preimplantation Bovine Embryo. PLoS One. 2013;8(6):e66230.

18. Hackett JA, Surani MA. DNA methylation dynamics during the mammalian life cycle. Philos Trans R Soc Lond B Biol Sci. 2013;368(1609):20110328.

19. Tang WY, Ho SM. Epigenetic reprogramming and imprinting in origins of disease. Rev Endocr Metab Disord. 2007;8(2):173-82.

20. Leroy JLMR, Vanholder T, Delanghe JR, Opsomer G, Van Soom A, Bols PEJ, Dewulf J, de Kruif A. Metabolic changes in follicular fluid of the dominant follicle in high-yielding dairy cows early post partum. Theriogenology. 2004;62(6):1131-43.

21. Robker RL, Akison LK, Bennett BD, Thrupp PN, Chura LR, Russell DL, Lane M, Norman RJ. Obese women exhibit differences in ovarian metabolites, hormones, and gene expression compared with moderate-weight women. J Clin Endocrinol Metab. 2009;94(5):1533-40.

22. Valckx SD, De Pauw I, De Neubourg D, Inion I, Berth M, Fransen E, Bols PE, Leroy JL. BMI-related metabolic composition of the follicular fluid of women undergoing assisted reproductive treatment and the consequences for oocyte and embryo quality. Hum Reprod. 2012;27(12):3531-9.

23. Vickers $\mathrm{MH}$. Early life nutrition, epigenetics and programming of later life disease. Nutrients. 2014;6(6):2165-78.

24. Barker DJP, Osmond C, Winter PD, Margetts B, Simmonds SJ. Originally published as Volume 2, Issue 8663WEIGHT IN INFANCY AND DEATH FROM ISCHAEMIC HEART DISEASE. Lancet. 1989;334(8663):577-80.

25. Ge Z-J, Liang X-W, Guo L, Liang Q-X, Luo S-M, Wang Y-P, Wei Y-C, Han Z-M, Schatten $\mathrm{H}$, Sun Q-Y. Maternal Diabetes Causes Alterations of DNA Methylation Statuses of Some Imprinted Genes in Murine Oocytes. Biol Reprod. 2013:88(5):117.

26. Jungheim ES, Louden ED, Chi MMY, Frolova Al, Riley JK, Moley KH. Preimplantation exposure of mouse embryos to palmitic acid results in fetal growth restriction followed by catch-up growth in the offspring. Biol Reprod. 2011;85(4):678-83.
27. Chen Z, Robbins KM, Wells KD, Rivera RM. Large offspring syndrome: A bovine model for the human loss-of-imprinting overgrowth syndrome Beckwith-Wiedemann. Epigenetics. 2013;8(6):591-601.

28. Katari S, Turan N, Bibikova M, Erinle O, Chalian R, Foster M, Gaughan JP, Coutifaris C, Sapienza C. DNA methylation and gene expression differences in children conceived in vitro or in vivo. Hum Mol Genet. 2009;18(20):3769-78.

29. Hart R, Norman RJ. The longer-term health outcomes for children born as a result of IVF treatment: Part I-General health outcomes. Hum Reprod Update. 2013;19(3):232-43

30. Leroy JLMR, Vanholder T, Mateusen B, Christophe A, Opsomer G, de Kruif A, Genicot G, Van Soom A. Non-esterified fatty acids in follicular fluid of dairy cows and their effect on developmental capacity of bovine oocytes in vitro. Reproduction. 2005;130(4):485-95.

31. Cagnone GLM, Dufort I, Vigneault C, Sirard M-A. Differential gene expression profile in bovine blastocysts resulting from hyperglycemia exposure during early cleavage stages. Biol Reprod. 2012;86(2):50.

32. Shojaei Saadi H, O'Doherty A, Gagne D, Fournier E, Grant J, Sirard M-A, Robert C. An integrated platform for bovine DNA methylome analysis suitable for small samples. BMC Genomics. 2014;15(1):451.

33. Marzluff WF, Gongidi P, Woods KR, Jin J, Maltais LJ. The human and mouse replication-dependent histone genes. Genomics. 2002;80(5):487-98.

34. Aagaard-Tillery KM, Grove K, Bishop J, Ke X, Fu Q, McKnight R, Lane RH. Developmental origins of disease and determinants of chromatin structure: maternal diet modifies the primate fetal epigenome. J Mol Endocrinol. 2008:41(2):91-102

35. Ge Z-J, Luo S-M, Lin F, Liang Q-X, Huang L, Wei Y-C, Hou Y, Han Z-M, Schatten H, Sun Q-Y. DNA methylation in oocytes and liver of female mice and their offspring: effects of high-Fat-diet-induced obesity. Environ Health Perspect. 2014;122(2):159-64.

36. Zhang $X$, Zhang K. Endoplasmic reticulum stress-associated lipid droplet formation and type II diabetes. Biochem Res Int. 2012;2012:247275.

37. Bilan PJ, Samokhvalov V, Koshkina A, Schertzer JD, Samaan MC, Klip A. Direct and macrophage-mediated actions of fatty acids causing insulin resistance in muscle cells. Arch Physiol Biochem. 2009;115(4):176-90.

38. Herbig K, Chiang E-P, Lee L-R, Hills J, Shane B, Stover PJ. Cytoplasmic serine hydroxymethyltransferase mediates competition between folate-dependent deoxyribonucleotide andS-adenosylmethionine biosyntheses. J Biol Chem. 2002;277(41):38381-9.

39. McCoy Claire E, Campbell David G, Deak M, Bloomberg Graham B, Arthur JSimon C. MSK1 activity is controlled by multiple phosphorylation sites. Biochem J. 2005;387(2):507-17.

40. Lu SC. Regulation of glutathione synthesis. Mol Asp Med. 2009;30(1-2):42-59.

41. Kirkegaard T, Jäättelä M. Lysosomal involvement in cell death and cancer. Biochim Biophys Acta. 2009;1793(4):746-54.

42. Du X, Kazim AS, Dawes IW, Brown AJ, Yang H. The AAA ATPase VPS4/SKD1 regulates endosomal cholesterol trafficking independently of ESCRT-III. Traffic 2013;14(1):107-19.

43. Komatsu M, Kageyama S, Ichimura Y. p62/SQSTM1/A170: Physiology and pathology. Pharmacol Res. 2012;66(6):457-62.

44. Ren W, Cheema S, Du K. The Association of ClipR-59 Protein with AS160 Modulates AS160 Protein Phosphorylation and Adipocyte Glut4 Protein Membrane Translocation. J Biol Chem. 2012;287(32):26890-900.

45. Balamatsias D, Kong AM, Waters JE, Sriratana A, Gurung R, Bailey CG, Rasko JEJ, Tiganis T, Macaulay SL, Mitchell CA. Identification of P-Rex1 as a novel Rac1-guanine nucleotide exchange factor (GEF) that promotes actin remodeling and GLUT4 protein trafficking in adipocytes. J Biol Chem. 2011;286(50):43229-40.

46. Yang WS, Lee WJ, Huang KC, Lee KC, Chao CL, Chen CL, Tai TY, Chuang LM. mRNA levels of the insulin-signaling molecule SORBS1 in the adipose depots of nondiabetic women. Obes Res. 2003;11(4):586-90.

47. Feldstein AE, Werneburg NW, Canbay A, Guicciardi ME, Bronk SF, Rydzewski R, Burgart LJ, Gores GJ. Free fatty acids promote hepatic lipotoxicity by stimulating TNF-a expression via a lysosomal pathway. Hepatology. 2004;40(1):185-94.

48. Hara T, Tanegashima K. Pleiotropic functions of the CXC-type chemokine CXCL14 in mammals. J Biochem. 2012;151(5):469-76.

49. Kotnik P, Fischer-Posovszky P, Wabitsch M. RBP4: a controversial adipokine. Eur J Endocrinol. 2011;165(5):703-11.

50. Zhou J, Chng W-J. Roles of thioredoxin binding protein (TXNIP) in oxidative stress, apoptosis and cancer. Mitochondrion. 2013;13(3):163-9. 
51. Smith CJ, Ryckman KK. Epigenetic and developmental influences on the risk of obesity, diabetes, and metabolic syndrome. Diabetes Metab Syndr Obes. 2015;8:295-302.

52. Pawitan Y, Michiels S, Koscielny S, Gusnanto A, Ploner A. False discovery rate, sensitivity and sample size for microarray studies. Bioinformatics. 2005;21(13):3017-24

53. Bird A. DNA methylation patterns and epigenetic memory. Genes Dev. 2002;16(1):6-21.

54. Salilew-Wondim D, Fournier E, Hoelker M, Saeed-Zidane M, Tholen E, Looft C, Neuhoff C, Besenfelder U, Havlicek V, Rings F, et al. Genome-wide DNA methylation patterns of bovine blastocysts developed in vivo from embryos completed different stages of development in vitro. PLoS One. 2015;10(11):e0140467.

55. Rekik W, Dufort I, Sirard M-A. Analysis of the gene expression pattern of bovine blastocysts at three stages of development. Mol Reprod Dev. 2011;78(4):226-40.

56. O'Doherty AM, Magee DA, O'Shea LC, Forde N, Beltman ME, Mamo S, Fair T. DNA methylation dynamics at imprinted genes during bovine pre-implantation embryo development. BMC Dev Biol. 2015;15:13.

57. Gad A, Hoelker M, Besenfelder U, Havlicek V, Cinar U, Rings F, Held E, Dufort I, Sirard M-A, Schellander K, et al. Molecular mechanisms and pathways involved in bovine embryonic genome activation and their regulation by alternative in vivo and in vitro culture conditions. Biol Reprod. 2012;87(4):100.

58. Cagnone GLM, Sirard M-A. Transcriptomic signature to oxidative stress exposure at the time of embryonic genome activation in bovine blastocysts. Mol Reprod Dev. 2013;80(4):297-314.

59. Lolicato F, Brouwers JF, de Lest CHA, Wubbolts R, Aardema H, Priore P, Roelen BAJ, Helms JB, Gadella BM. The cumulus cell layer protects the bovine maturing oocyte against fatty acid-induced lipotoxicity. Biol Reprod. 2015:92(1):16.

60. Aardema $\mathrm{H}$, Lolicato $F$, van de Lest CHA, Brouwers JF, Vaandrager AB, van Tol HTA, Roelen BAJ, Vos PLAM, Helms JB, Gadella BM. Bovine cumulus cells protect maturing oocytes from increased fatty acid levels by massive intracellular lipid storage. Biol Reprod. 2013;88(6):164.

61. Dunning KR, Russell DL, Robker RL. Lipids and oocyte developmental competence: the role of fatty acids and $\beta$-oxidation. Reproduction. 2014:148(1):R15-27.

62. Thompson JG, Partridge RJ, Houghton FD, Cox Cl, Leese HJ. Oxygen uptake and carbohydrate metabolism by in vitro derived bovine embryos. J Reprod Fertil. 1996;106(2):299-306.

\section{Submit your next manuscript to BioMed Central and we will help you at every step:}

- We accept pre-submission inquiries

- Our selector tool helps you to find the most relevant journal

- We provide round the clock customer support

- Convenient online submission

- Thorough peer review

- Inclusion in PubMed and all major indexing services

- Maximum visibility for your research

Submit your manuscript at www biomedcentral.com/submit

) Biomed Central 